\title{
Seismic tomography of the uppermost mantle beneath southwestern Japan: Seismological constraints on modelling subduction and magmatism for the Philippine Sea slab
}

\author{
S. Honda and I. Nakanishi \\ Department of Geophysics, Kyoto University, Kyoto 606-8502, Japan \\ (Received April 2, 2003; Revised September 8, 2003; Accepted September 11, 2003)
}

\begin{abstract}
Many studies have been made on the subduction of the Pacific slab and the magmatism in northeastern Japan, but not on the subduction of the Philippine Sea slab and the magmatism in southwestern Japan. Primary reasons may be that seismological networks in southwestern Japan were sparse as compared with those in northeastern Japan and that geology including volcanism of southwestern Japan is more complicated than that of northeastern Japan. However, recent instrumental development of dense seismological networks in the Japanese Islands has provided us with high quality data not only for northeastern Japan but for southwestern Japan. One of the outcomes from the development is the increase of accuracy of arrival time readings of $P$ - and $S$-waves and resultant hypocenter determination. We attempt to elucidate fine image of the uppermost mantle structure beneath the Japanese Islands and to find evidence for the relation between the magmatism and subduction process. We apply travel time tomography to $216,247 P$ - and 98,207 $S$-wave arrival times observed at 1,328 seismic stations from 5,242 earthquakes in and around the Japanese Islands, and obtain three-dimensional variations of $P$ - and $S$-wave velocity structure. In Chubu and Kyushu, the subducting Philippine Sea slab bends downward in the depth range of 50 to 70 $\mathrm{km}$. In some nonvolcanic regions, remarkable anomalies of high Poisson's ratio (and low $S$-wave velocity) are seen in the depth range of 25 to $40 \mathrm{~km}$ near the upper boundary of the Philippine Sea slab or the Moho discontinuity, and approximately coincide with the hypocenter distribution of deep low-frequency earthquakes. The anomalies of high Poisson's ratio are also seen near the upper boundary of the Philippine Sea slab or the overlying mantle wedge down to a depth of about $60 \mathrm{~km}$, but are not seen after the downward bending of the slab, in the forearc region. The anomalies are probably caused by separated fluid or hydrous minerals. These characteristics should be taken into account in numerical modelling of the subduction of young slabs (e.g., Philippine Sea slab) and associated phenomena (e.g., magmatism).
\end{abstract}

Key words: Seismic tomography, young plate, Philippine Sea plate, aseismic slab, deep low frequency earthquake, high Poisson's ratio.

\section{Introduction}

In the Japanese Islands, the young Philippine Sea plate (PHS plate) is subducting from the southeast beneath the Eurasian plate, and the old Pacific plate (PAC plate) is subducting from the east beneath the PHS and Eurasian plates (Fig. 1). The subduction of the PHS and PAC plates causes complicated surface geology and the lateral heterogeneities in the upper mantle beneath the Japanese Islands.

Many Quaternary volcanoes occur in the Japan arcs (Fig. 1). In Tohoku, a clear volcanic front is formed parallel to the Japan Trench, and coincides with the $110 \mathrm{~km}$ isodepth line of subcrustal earthquakes occurring in the PAC slab. This fact suggests that the subducting slabs play important roles in the arc volcanism, thus many petrologists have proposed possible models which explain the magma generation in subduction zones (e.g., Tatsumi, 1989; Iwamori, 1998; Mibe et al., 1999). Iwamori (1998) has argued from numerical simulations of fluid migration that nearly all the $\mathrm{H}_{2} \mathrm{O}$ expelled from a cold slab ( $\sim 130 \mathrm{Myr})$ is hosted by serpen-

Copy right(C) The Society of Geomagnetism and Earth, Planetary and Space Science (SGEPSS); The Seismological Society of Japan; The Volcanological Society of Japan; The Geodetic Society of Japan; The Japanese Society for Planetary Sciences. tine and chlorite at the base of the mantle wedge right above the subducting slab, and then is released at a depth of about $150 \mathrm{~km}$ with the breakdown of serpentine and is transported upwards to cause partial melting of the mantle wedge on the backarc side. Mibe et al. (1999) have obtained the experimental relation between the dihedral angle at the triple junctions between mineral grains and aqueous fluid in the mantle wedge, and then have suggested that the magmatism beneath the volcanic front is initiated in the region where interconnected network of $\mathrm{H}_{2} \mathrm{O}$ is formed and the aqueous fluid is supplied from downdragged hydrous peridotite. These models of magma generation in subduction zones indicate the necessity of the following two processes: the transfer of hot mantle materials from the deeper region by the mantle wedge convection induced by the subduction of the underlying slab, and the generation of fluid by the dehydration of the oceanic crust subducted with the slab which lowers the solidus temperature of mantle wedge peridotite. The interaction of the two processes is considered to result in the arc magmatism.

The results of seismic tomography introduce useful information about the two processes. In Tohoku, seismic tomography has been applied to reveal 3-D velocity structure in the 


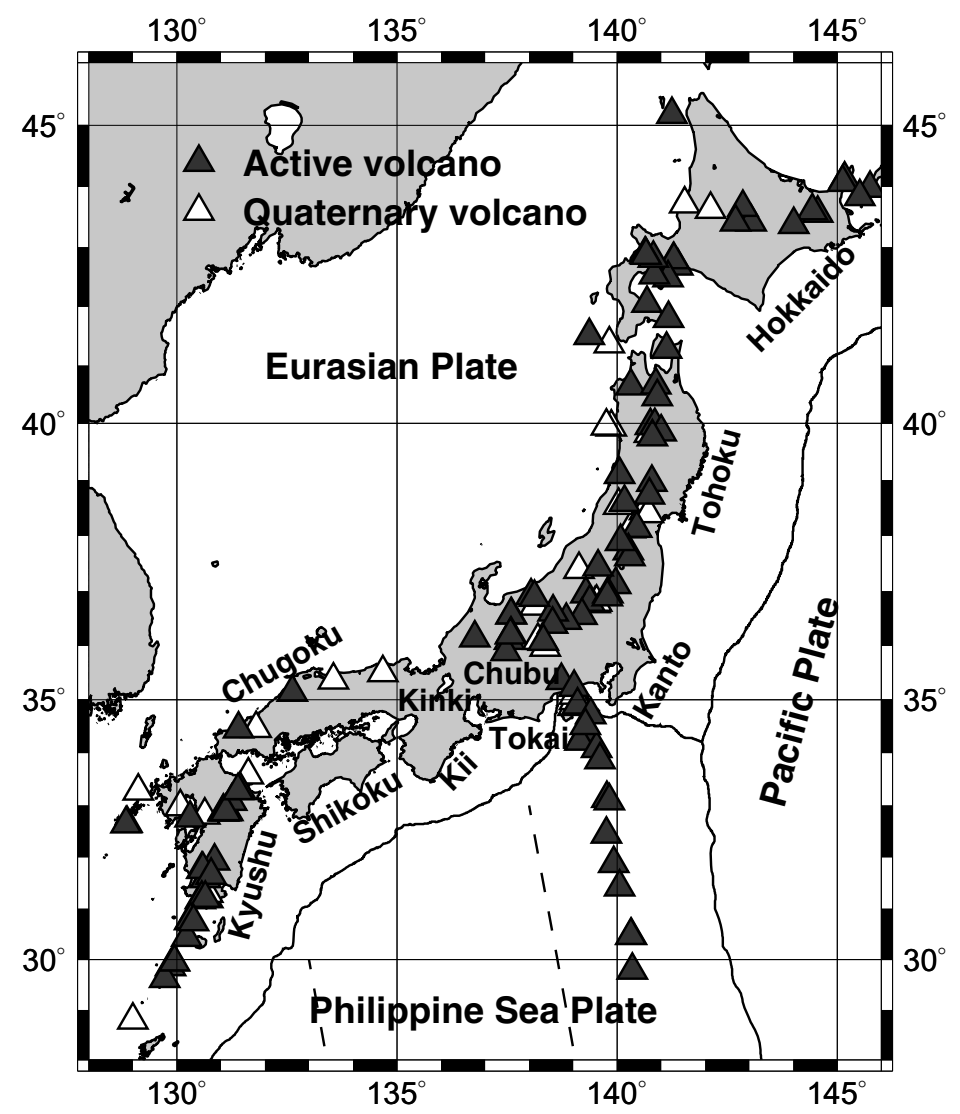

Fig. 1. Volcanoes and plates in and around the Japanese Islands. Solid triangles indicate presently active volcanoes reported by the Japan Meteorological Agency $(2002,2003)$. Open triangles indicate other Quaternary volcanoes reported by Aramaki and Ui (1978).

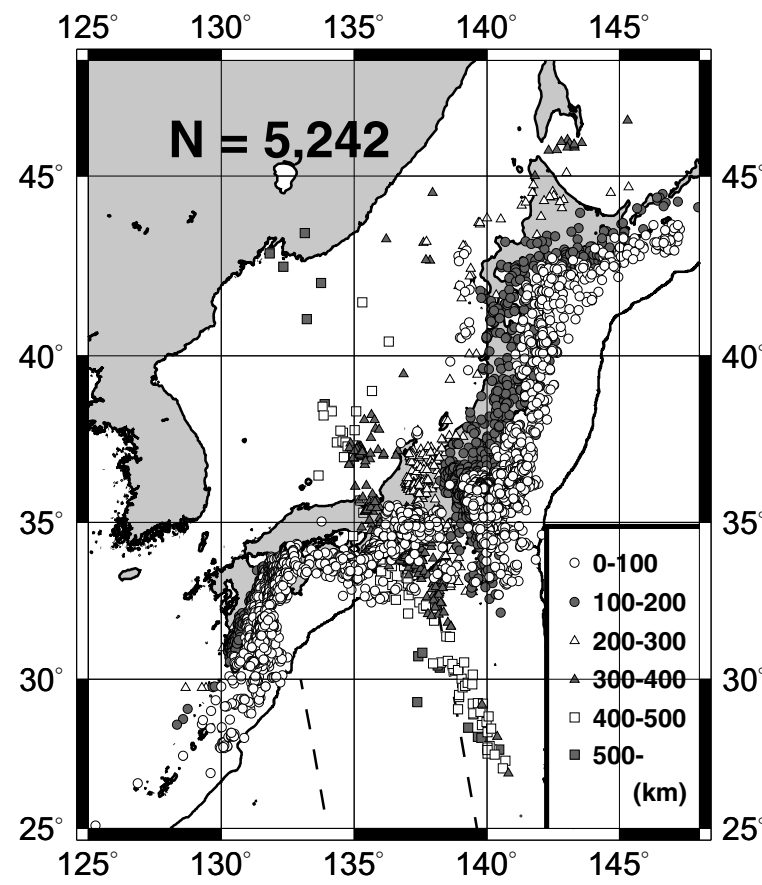

(a)

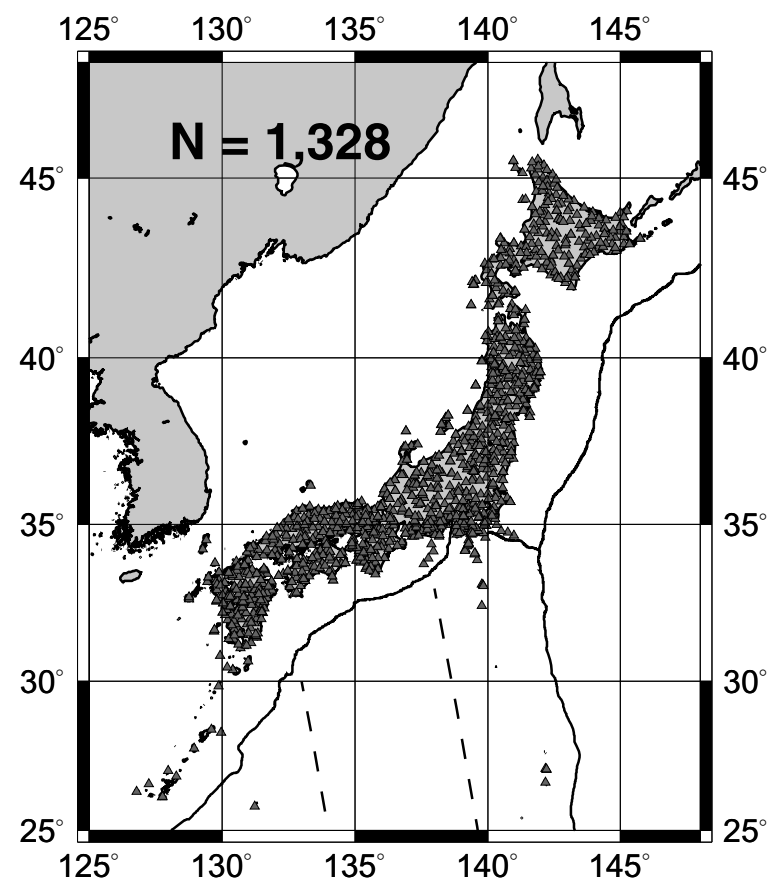

(b)

Fig. 2. (a) Epicentral distribution of 5,242 earthquakes used in this study. (b) Distribution of 1,328 stations used in this study. 


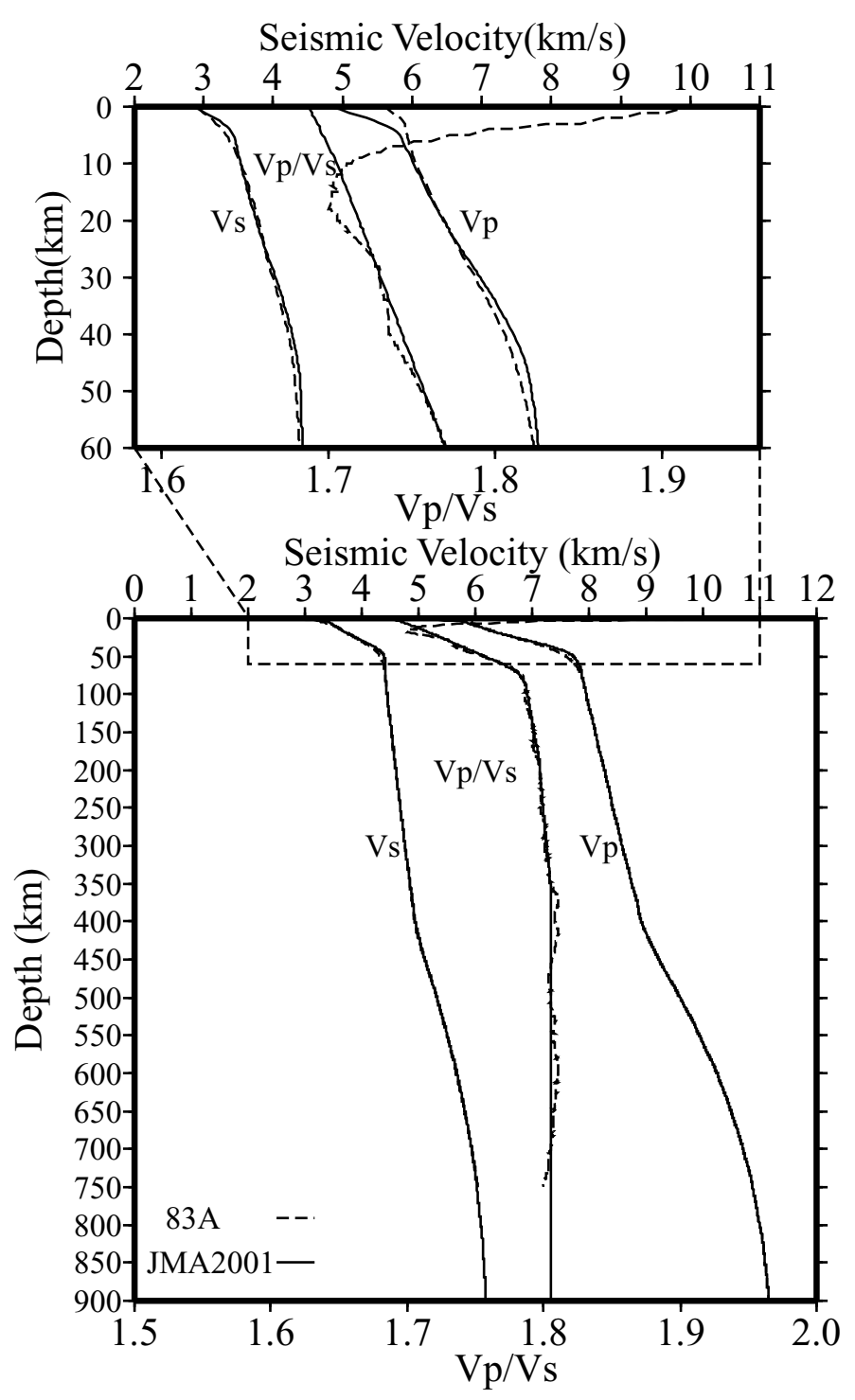

Fig. 3. JMA2001, one-dimensional continuous reference velocity model used in this study (Ueno et al., 2002).

upper mantle, using dense seismic station networks (Zhao et al., 1992; Nakajima et al., 2001). They found the high velocity (HV) anomalies indicating the PAC slab and the low velocity (LV) anomalies indicating the ascending mantle flow from the deeper mantle wedge in the backarc side to the crust beneath active volcanoes.

In contrast, the mechanism of magma generation related to the PHS slab beneath southwestern Japan is poorly understood. The shape of the seismic PHS slab has been studied from hypocenter distribution of subcrustal earthquakes (Yamazaki and Ooida, 1985; Kinoshita and Nakanishi, 1997; Nakamura et al., 1997; Miyoshi and Ishibashi, 2002; Nakanishi et al., 2002). However, the analyses of $S$ to $P$ converted waves have suggested that aseismic PHS slab is located beyond the northern edge of the seismic PHS slab (Nakanishi, 1980; Nakanishi et al., 1981; Yamaoka and Nishihara, 1997; Oda and Douzen, 2001). Numerical experiments on the thermal evolution of subducting slab and mantle wedge suggest that the faster or the more deeply a slab subducts, the more extensively hot mantle materials spread over the mantle wedge (e.g., Kincaid and Sacks, 1997), therefore the deter- mination of the 3-D seismic structure including the detailed shape of the PHS slab is required to reveal the mantle wedge convection.

Obara (2002) has located deep low-frequency (DLF) tremors above the slab surface at depths of about 35 to $45 \mathrm{~km}$ along the strike of the dipping PHS slab in nonvolcanic regions in southwestern Japan (beneath Shikoku, the Kii peninsula, and Tokai) (Fig. 1) using the data of Hi-net, densely distributed high-sensitivity seismic stations operated by the National Research Institute for Earth Science and Disaster Prevention. Considering the long duration and the mobility of the tremor activity, he has pointed out that the generation of the tremors is related to the movement of fluid liberated by the dehydration of the underlying PHS slab. The knowledge of the behavior of the fluid released from the PHS slab will constrain the modelling of the magmatism for southwestern Japan.

Regional tomographic studies of seismic velocity structure beneath southwestern Japan have provided important information about the PHS slab and overlying mantle wedge (Hirahara, 1981; Zhao et al., 2000a, 2000b; Yamane et al., 2000; 


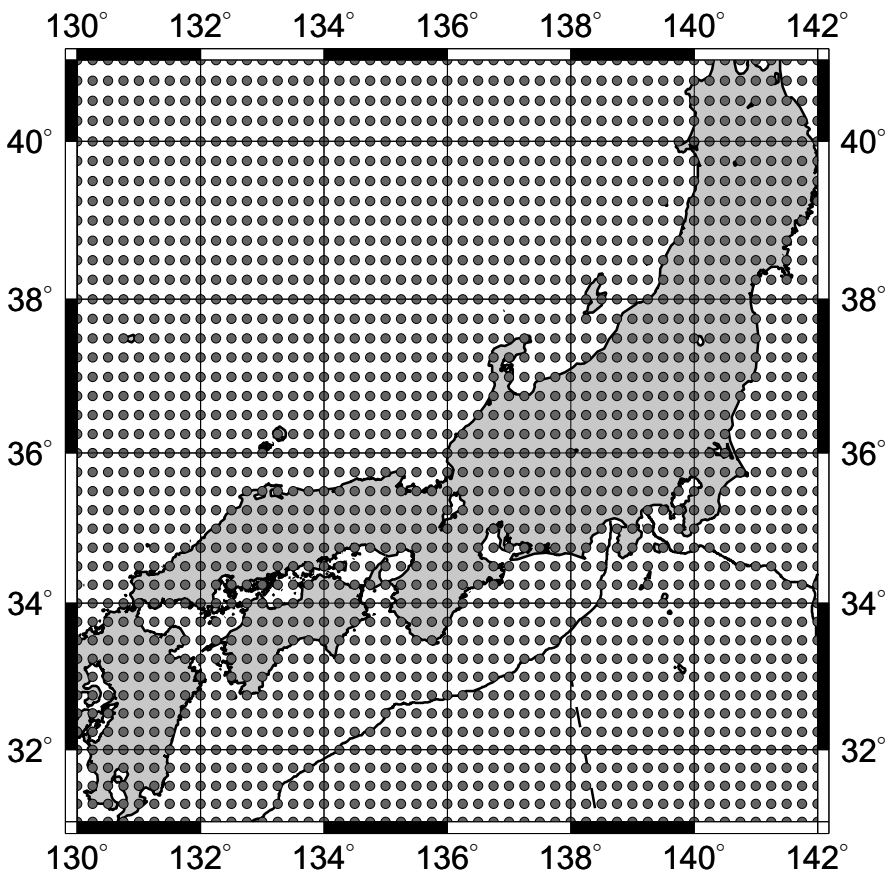

(a)

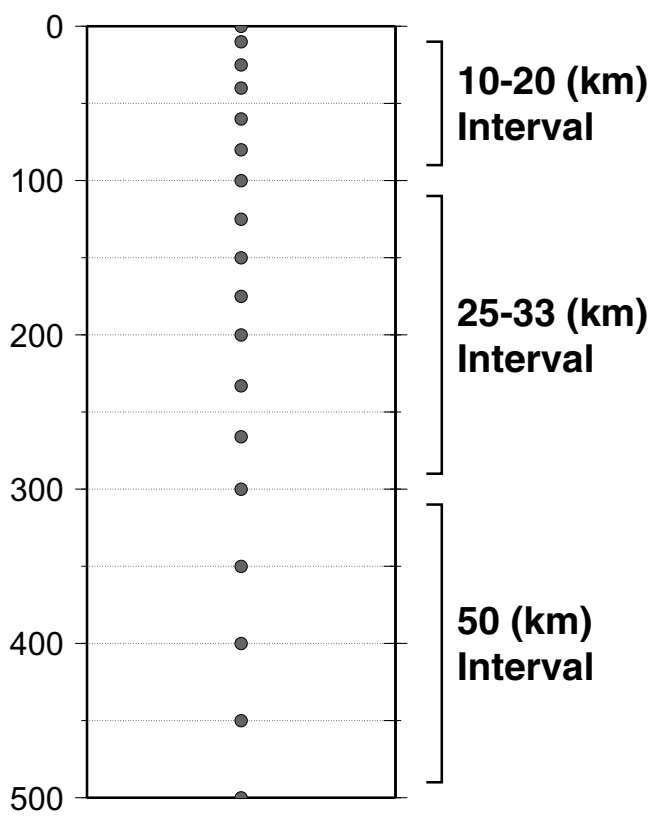

(b)

Fig. 4. (a) Horizontal and (b) vertical distributions of grid points used in this study.

Honda and Nakanishi, 2002; Nakamura et al., 2002).

In October 1997, the Japan Meteorological Agency (JMA) upgraded their seismic network and earthquake location method. Tomographic study using a large amount of these high quality arrival time data will provide more reliable uppermost mantle images including the shape of the PHS slab than those in the previous works. The purpose of this study is to determine a fine 3-D velocity structure of the uppermost mantle beneath southwestern Japan by applying a tomographic method to the latest data, and to obtain new knowledge about the subduction and magmatism for the PHS slab.

\section{Data and Analysis Method}

The 3-D structure beneath southwestern Japan is the subject of this study, but we use hypocenter data and seismic stations located in and around the Japanese Islands to include the rays penetrating into the deep mantle. Therefore we determine velocity structure beneath southwestern and northeastern Japan.

We use hypocenter and $P$ - and $S$-wave arrival time data during the period from July 1985 to September 1994 (for about 10 years) reported in the Japan University Network Earthquake Catalog (JUNEC data), from October 1994 to September 1997 (for 3 years) reported in the Seismological and Volcanological Bulletin of Japan published by the JMA (JMA data), and from October 1997 to June 2002 (for about 5 years) processed with close coordination of the JMA with the Ministry of Education, Culture, Sports, Science and Technology (JMME data). The JMME data consist of the records observed by dense seismic station networks covering the Japanese Islands, therefore these data will provide reliable results of velocity structure. The selection of hypocenters is based on the following criteria: (1) The number of initial $P$-wave arrivals is larger than 30 , and that of initial
$S$-wave arrivals is larger than 3. (2) The depth of hypocenter is greater than $33.5 \mathrm{~km}$ to remove the influence of head waves, because they are not considered in those arrival time data. (3) The error in origin time is less than $0.5 \mathrm{~s}$, and those in latitude, longitude and depth are less than $5.0 \mathrm{~km}$. We eliminate the arrival times with epicentral distances greater than $10^{\circ}$ or with travel time residuals greater than $5.0 \mathrm{~s}$ for $P$-wave or $10.0 \mathrm{~s}$ for $S$-wave. Consequently we have selected 5,242 earthquakes (Fig. 2(a)), 216,247 $P$-wave arrival times, 98,207 $S$-wave arrival times, and 1,328 seismic stations (Fig. 2(b)).

We use spherically symmetric and continuous velocity model JMA2001 (Ueno et al., 2002) as the reference velocity model (Fig. 3). The locations of hypocenters reported in the JUNEC data and the JMA data are calculated by velocity model 83A (Hamada, 1984), and we relocate these hypocenters by using JMA2001 before 3-D inversion. As the model space, we take the longitude range of $128^{\circ} \mathrm{E}-145^{\circ} \mathrm{E}$, the latitude range of $28^{\circ} \mathrm{N}-45^{\circ} \mathrm{N}$, and the depth range of $0-500 \mathrm{~km}$. We discretize the model space by grids to represent the 3-D velocity structure, with a horizontal grid interval of $0.25^{\circ} \times$ $0.25^{\circ}$ (Fig. 4(a)), and vertical grid intervals of $10 \mathrm{~km}$ to 50 $\mathrm{km}$ (Fig. 4(b)). The use of grid intervals smaller than the above ones leads to inaccurate tomographic images.

Since we adopt the pseudo-bending method (Um and Thurber, 1987) for ray tracing in the heterogeneous earth model, we iterate linear-inversion five times, using ARTB method (Hirahara, 1988) for the solution of observation equations. The original algorithm of the pseudo-bending method is applicable only in the Cartesian coordinates (Um and Thurber, 1987). In this study, we modify the method and apply it to ray tracing in the spherical coordinates. The root mean squares (RMS) of the travel time residuals decrease monotonously with the iteration, from $0.630 \mathrm{~s}$ to $0.265 \mathrm{~s}$ for 


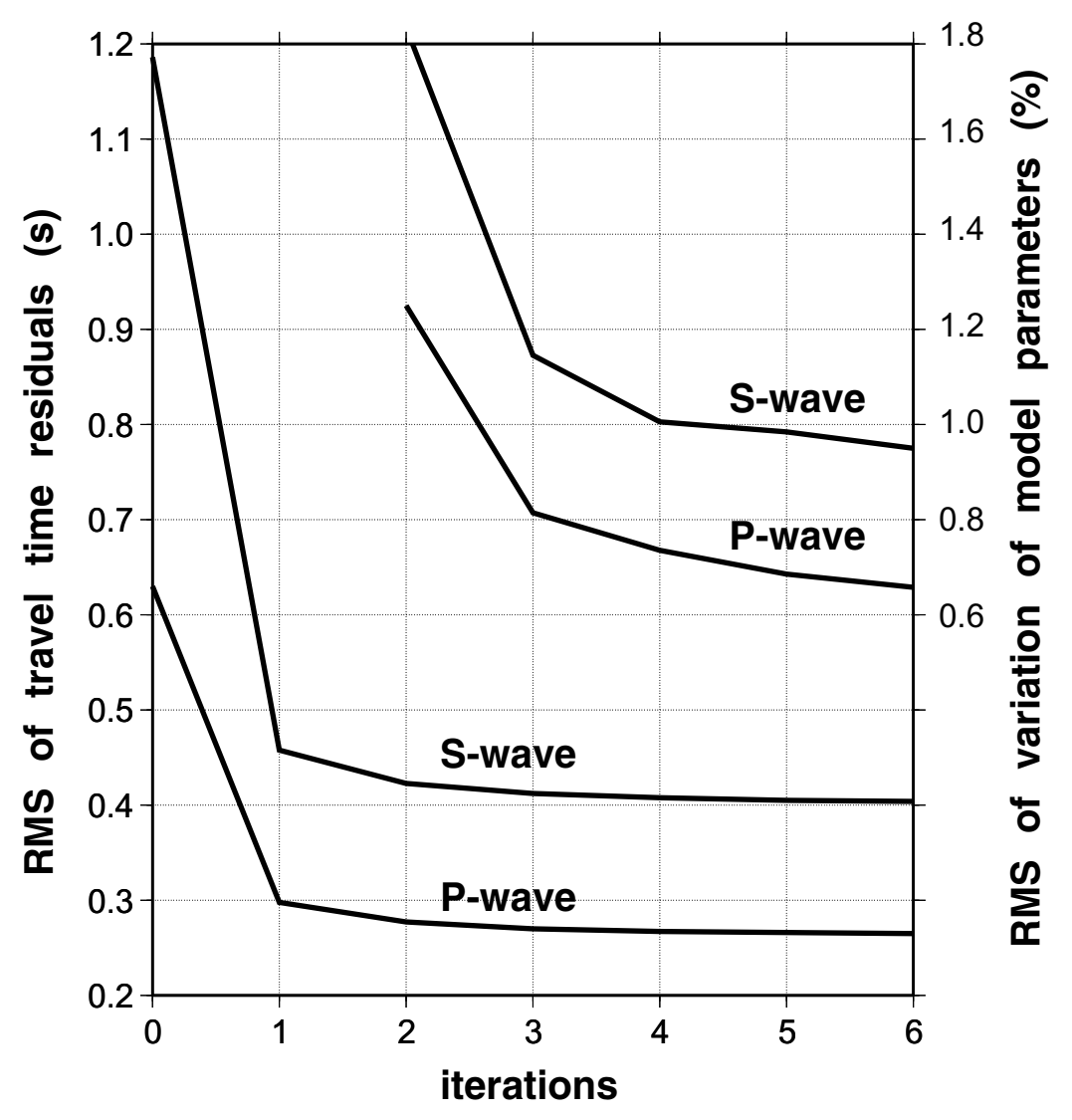

Fig. 5. Root mean squares of travel time residuals and those of variation of slowness perturbations, versus the number of iterations in the non-linear inversion.

$P$-wave and from $1.186 \mathrm{~s}$ to $0.404 \mathrm{~s}$ for $S$-wave (Fig. 5). The RMS of the variations of slowness perturbations also decreases with the iteration (Fig. 5). We determine a total of 96,756 unknown parameters simultaneously, consisting of 40,249 $P$-wave slowness perturbations, 32,883 $S$-wave slowness perturbations, $5,242 \times 4$ source parameter corrections, and $1,328 \times 2 P$ - and $S$-wave station corrections. The structure of Poisson's ratio is calculated from the obtained $P$ - and $S$-wave velocity perturbations. We use checkerboard resolution test (Inoue et al., 1990) to estimate the reliability of the obtained 3-D structure. The values of assumed checkerboard-type perturbations assigned to each grid are $\pm 3 \%$.

\section{High Poisson's Ratio Anomalies and Deep Low-Frequency Earthquakes -Horizontal Cross Sections-}

Figures 6-10 show the slowness perturbations of $P$ - and $S$-wave, checkerboard resolutions of $P$ - and $S$-wave, and Poisson's ratios at five depths of upper $100 \mathrm{~km}$ in the crust and mantle. The images at depths of 0 and $10 \mathrm{~km}$ lack resolutions because they are determined by nearly vertical rays beneath stations and have trade-off with the station corrections, and we do not show the results on these depths in this paper.

Figures 6(a) and (b) show the slowness perturbations at the depth of $25 \mathrm{~km}$, representing the structure in the lower crust or around the Moho discontinuity. At this depth, the resolutions of $P$-wave slowness perturbations are good beneath the land, and those of $S$-wave slowness perturbations are also good beneath the land except in the western part of Tohoku and in the northern part of Chugoku. The poor resolutions are generally due to insufficient lengths and directions of the rays traveling in the areas.

In Fig. 6(c), we find remarkable high Poisson's ratio (HP) amomalies beneath southwestern Japan, extending from Tokai to the Pacific coast of the southeastern part of Kyushu. These HP anomalies coincide with the $30-40 \mathrm{~km}$ isodepth line of the upper boundary of the PHS slab except in the central part of Kinki, and this distribution of the HP anomalies shows fairly good similarity to that of the DLF earthquakes reported by Obara (2002) in Tokai and Shikoku. He suggests that these DLF earthquakes are generated by the moving fluid near the upper boundary of the PHS slab or the Moho discontinuity. Therefore the HP anomalies in these regions (Fig. 6(c)) may be the evidence for the fluid.

The DLF earthquakes are seen in the JMME data as well (Fig. 11(a)). Considering the locations of epicenters, we divide them into two groups: DLF earthquakes generated by the influence of magma in volcanic regions and those generated by the influence of fluid in nonvolcanic regions. Figure 11(b) shows the depth distribution of the DLF earthquakes seen in the JMME data for volcanic regions and nonvolcanic three regions. The DLF earthquakes are located mainly in the depth range of $25-35 \mathrm{~km}$ in Shikoku where the HP anomalies are seen at the depth of $25 \mathrm{~km}$ in Fig. 6(c). In the southern part of the Kii peninsula where notable HP anomalies are not found at the depth of $25 \mathrm{~km}$, the DLF 


$$
\text { depth }=25(\mathrm{~km})
$$
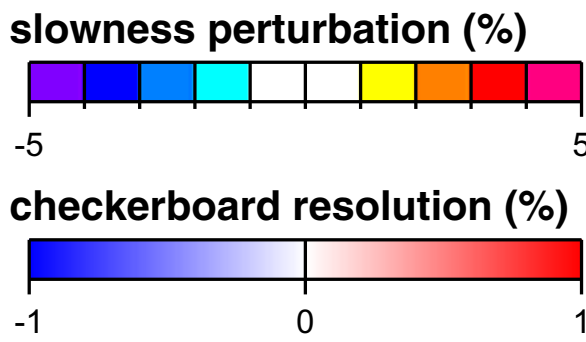

Poisson's ratio
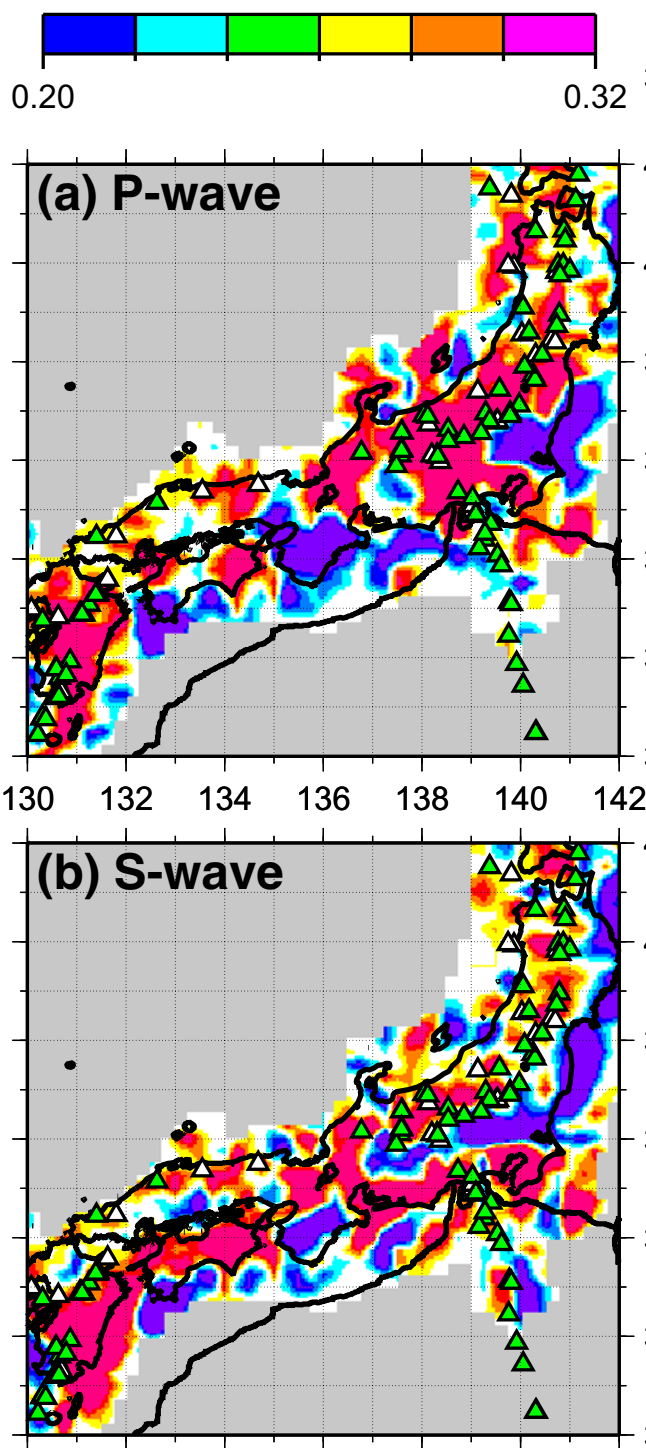
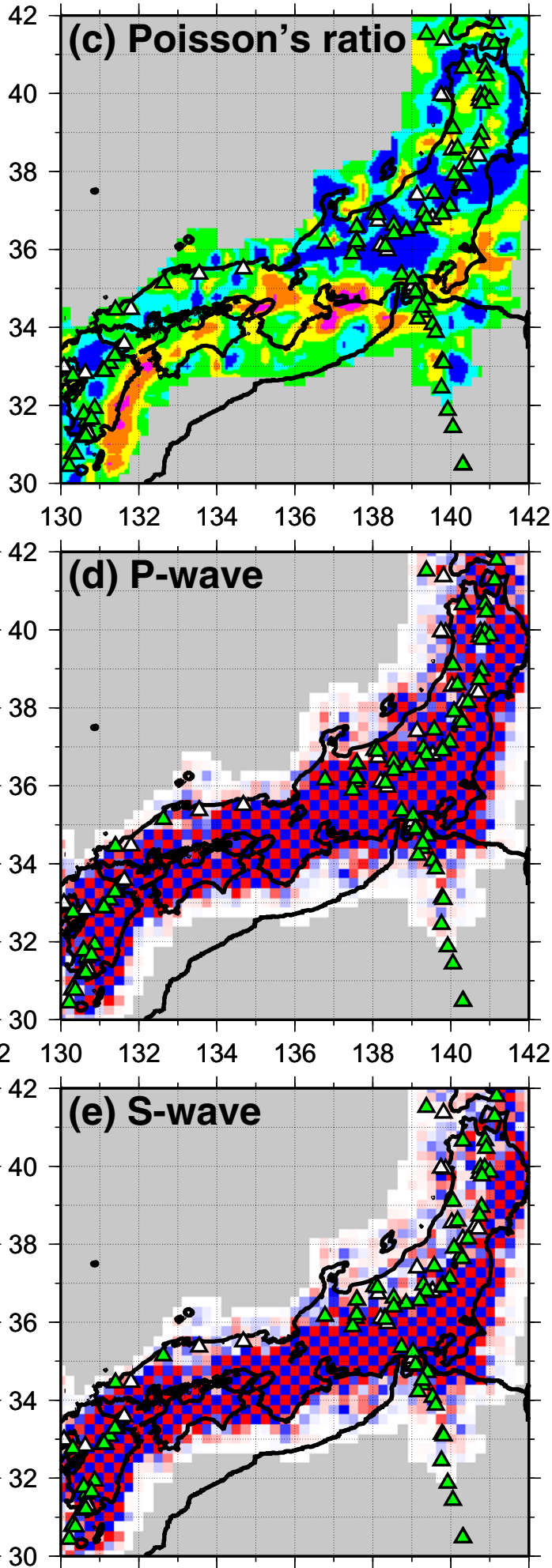

Fig. 6. Horizontal cross sections of slowness perturbations ((a) $P$-wave and (b) $S$-wave), (c) Poisson's ratio, and checkerboard resolutions ((d) $P$-wave and (e) $S$-wave) at the depth of $25 \mathrm{~km}$. In the figures of the slowness perturbations, cold and hot colors denote high and low velocity anomalies compared to the reference velocity model, respectively. In the figure of the Poisson's ratio, cold and hot colors denote low and high Poisson's ratio anomalies, respectively. In the figures of the checkerboard resolutions, the resolutions are good in the region where the assumed checkerboard-type perturbations are well reconstructed. Solid and open triangles indicate presently active and inactive Quaternary volcanoes, respectively.

earthquakes are located mainly in the depth range of 30-40 km (Fig. 11(b)). Figure 7(c) shows that the HP anomalies in Kii region are seen at the depth of $40 \mathrm{~km}$. In Tokai, where the DLF earthquakes are located in the depth range of 20-45 $\mathrm{km}$, the HP anomalies are remarkable at the depths of $25 \mathrm{~km}$
(Fig. 6(c)) and $40 \mathrm{~km}$ (Fig. 7(c)). The correlation between the HP anomalies and the DLF earthquakes in the three regions may suggest the presence of the moving fluid. The standard errors in the location of the DLF earthquakes in the JMME data are $0.68 \mathrm{~km}, 0.73 \mathrm{~km}$, and $1.50 \mathrm{~km}$ for longitude, 


\section{depth $=\mathbf{4 0}(\mathbf{k m})$}
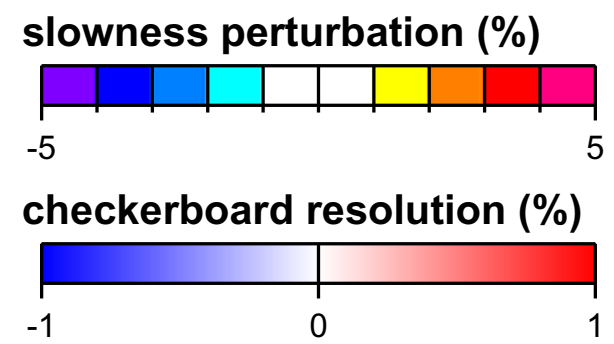

Poisson's ratio
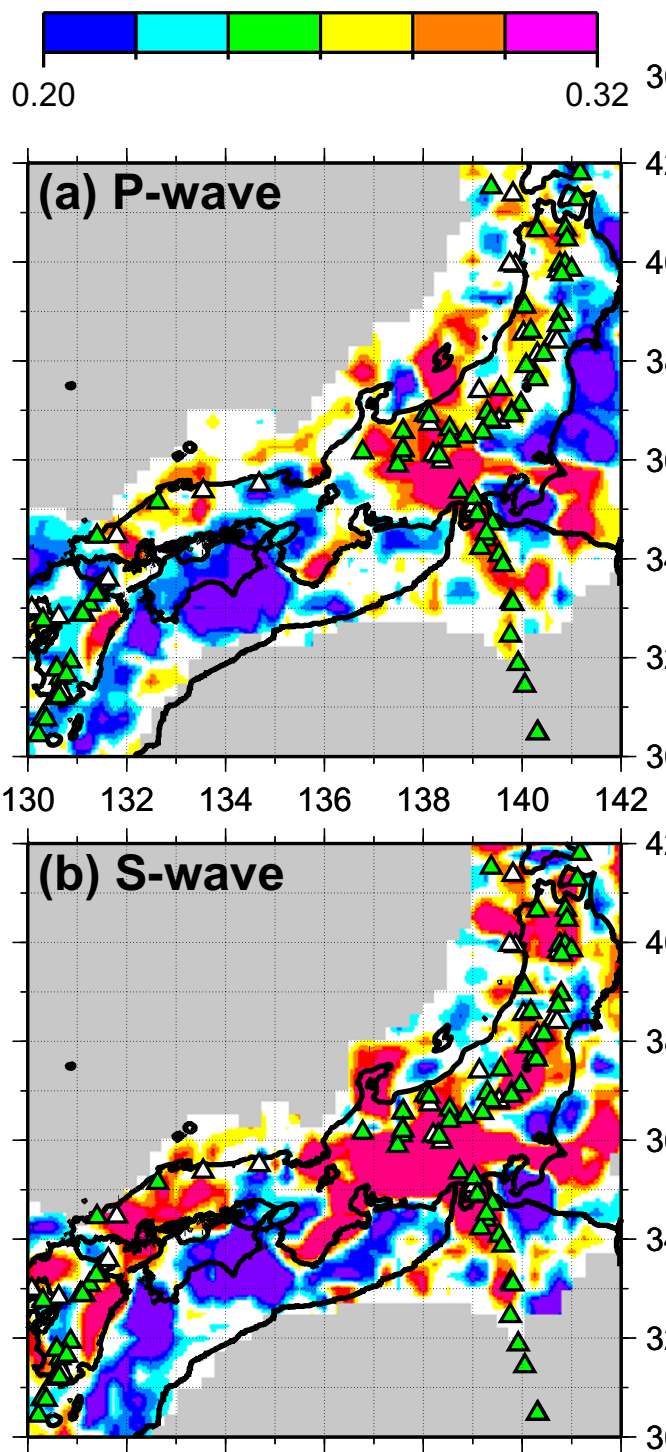
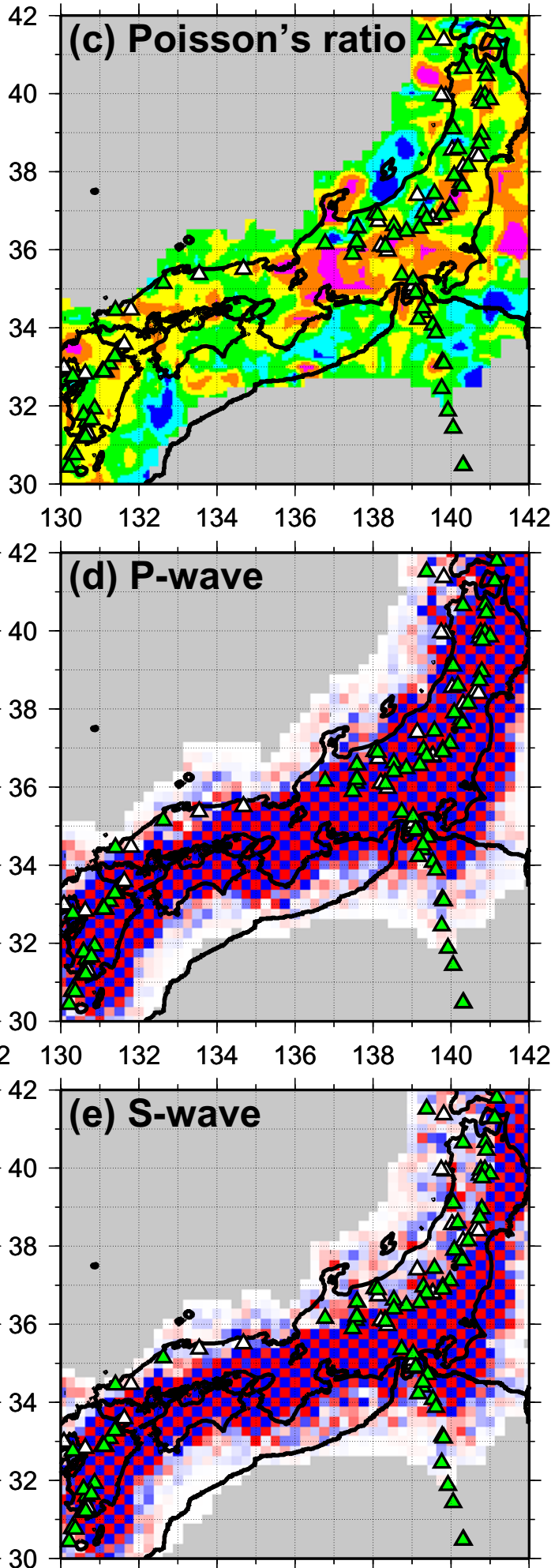

Fig. 7. Same as Fig. 6 except for the depth of $40 \mathrm{~km}$.

latitude, and depth. Therefore this high correlation may be considered as significant.

The correlation is not significant beneath active volcanoes in Tohoku, Kanto, Chubu, and Kyushu. Beneath active volcanoes, the DLF earthquakes are located mainly in the depth range of 10-35 km (Fig. 11(b)). We find no clear HP anomalies at the depth of $25 \mathrm{~km}$ (Fig. 6(c)), but clear HP anomalies spread at the depth of $40 \mathrm{~km}$ (Fig. 7(c)). Since LV anoma- lies of $S$-wave appear at the depth of $25 \mathrm{~km}$ beneath active volcanoes, we cannot deny the presence of magma or fluid at this depth. The mechanism of the generation of the DLF earthquakes in volcanic regions may be different from that in nonvolcanic regions: the local ascents of melt or volatile materials such as $\mathrm{H}_{2} \mathrm{O}$ and $\mathrm{CO}_{2}$ from magma chamber under the Moho discontinuity might generate the DLF earthquakes in volcanic regions. However, the identification of the gen- 


$$
\text { depth }=60(\mathrm{~km})
$$
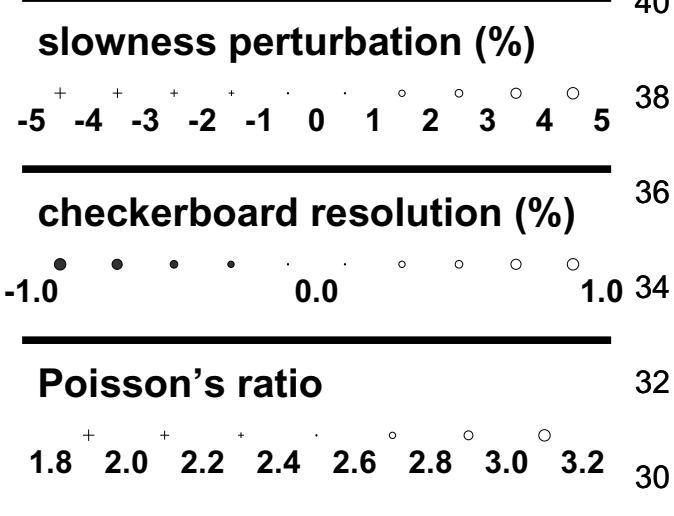
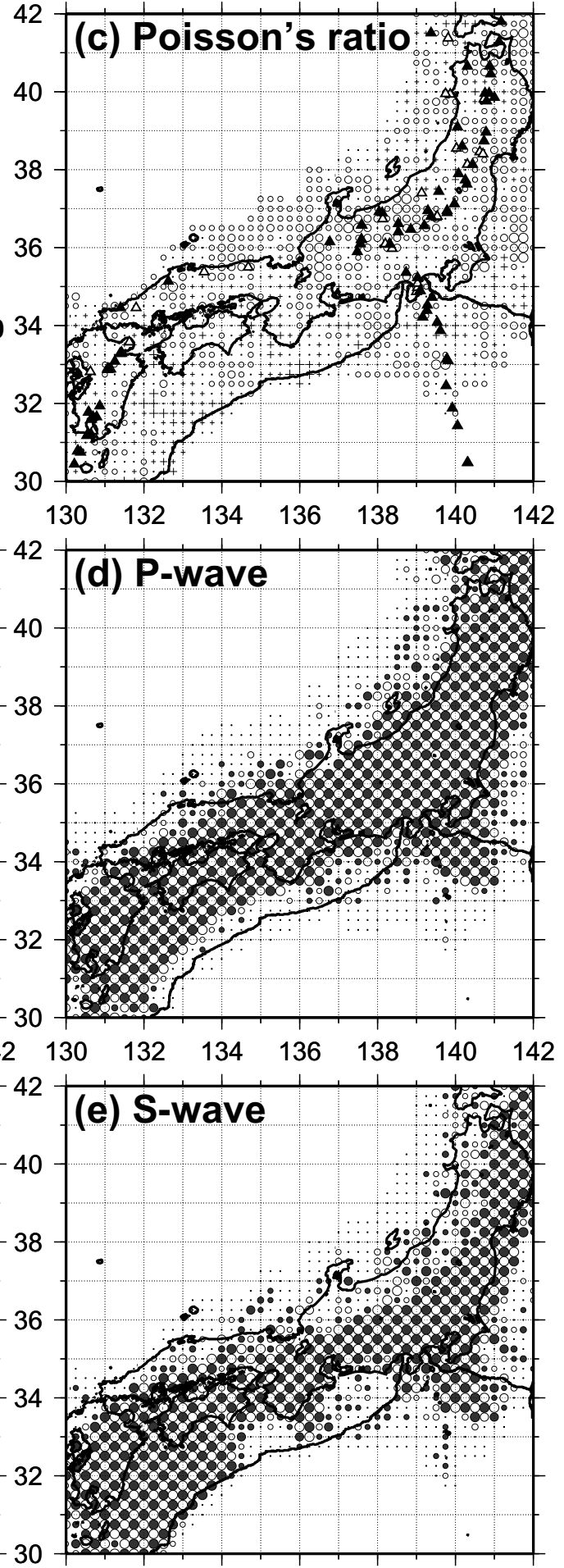

Fig. 8. Same as Fig. 6 except for the depth of $60 \mathrm{~km}$ and symbol conventions. In the figures of slowness perturbations, crosses and circles denote high and low velocity anomalies, respectively. In the figure of Poisson's ratio, crosses and circles denote low and high Poisson's ratio anomalies, respectively.

eration mechanism is beyond the scope of the tomographic study in this paper.

Few DLF earthquakes have been observed off the Pacific coast of Kyushu (Fig. 11(a)) where prominent HP anomalies appear at the depth of $25 \mathrm{~km}$ (Fig. 6(c)). It must be due to poor detectability for the DLF earthquakes in this region: small amplitudes of the DLF earthquakes make it difficult to observe them in the offshore region of Kyushu by the present network deployed in land. Network of ocean bottom seis- mometers is required to solve this problem. The average of magnitudes of the DLF earthquakes in nonvolcanic regions reported in the JMME data is 0.8 . We show the relation between the HP anomalies in nonvolcanic regions and the PHS slab later in the vertical cross sections of the slowness perturbations.

At the depth of $60 \mathrm{~km}$ (Fig. 8), LV anomalies of both $P$ and $S$-wave are running along the volcanic front from Tohoku to the Izu peninsula. HV anomalies of both $P$ - and $S$ - 


\section{depth $\mathbf{=} \mathbf{8 0}(\mathbf{k m})$}
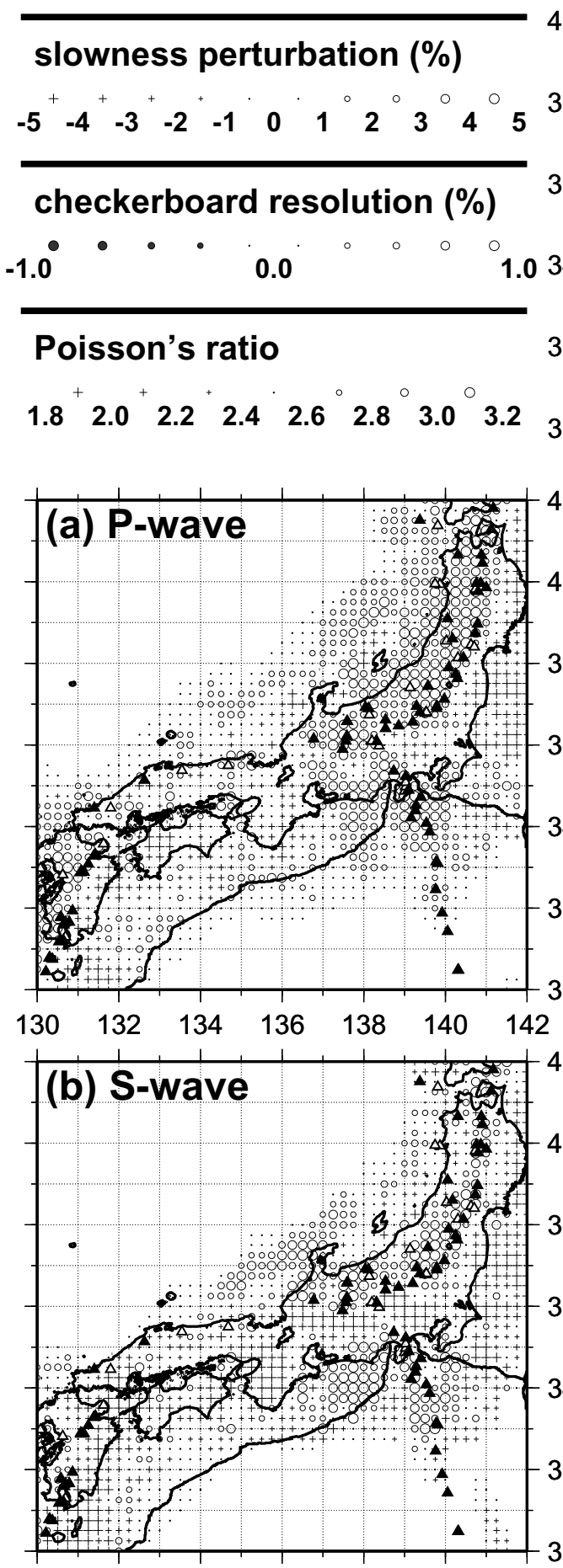
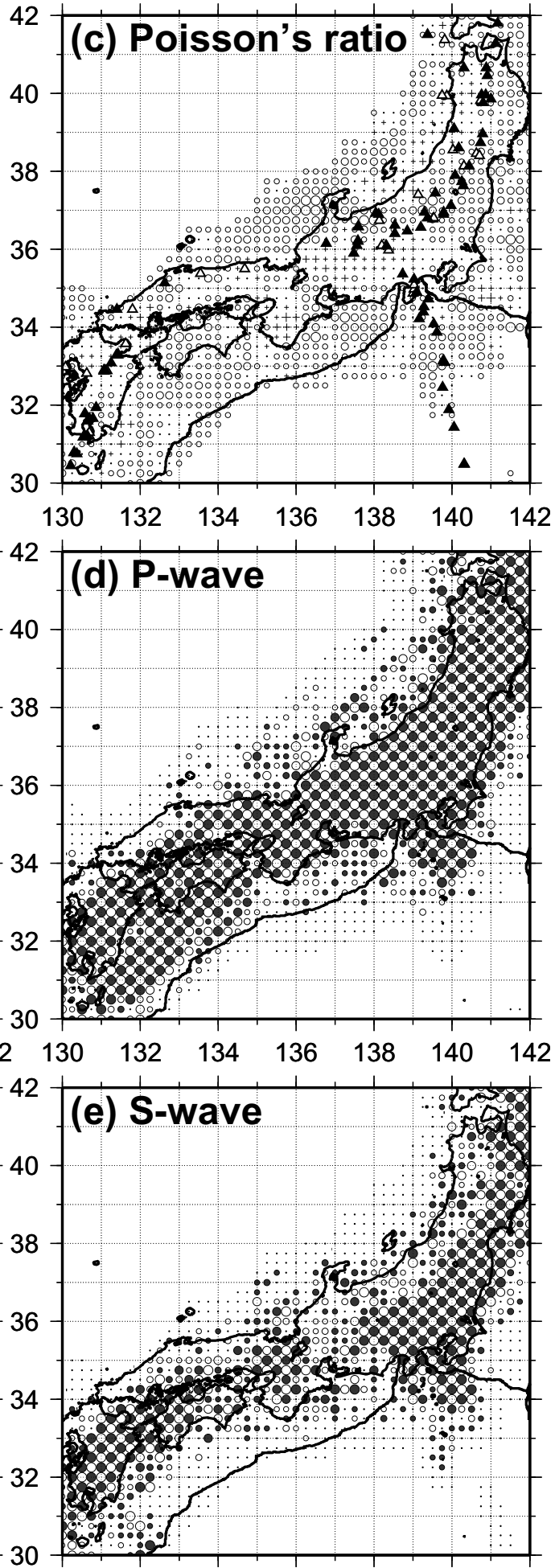

Fig. 9. Same as Fig. 8 except for the depth of $80 \mathrm{~km}$.

wave corresponding to the subducting PHS slab are clearly seen beneath Shikoku Island, and the anomalies of $S$-wave are clear also in the result of Chugoku. However, in the northern part of Chugoku, the resolutions of both $P$ - and $S$-wave are low. In the images of $S$-wave slowness perturbations, remarkable LV anomalies are located in the Kii peninsula in the middle of the continuous HV anomalies corresponding to the PHS slab. This unusual feature appears also in the images of $P$-wave slowness perturbations and in the results of Zhao et al. (2000a) and Yamane et al. (2000). In the result of $P$-wave slowness perturbations, the HV anomalies indicating the PHS slab extend from the southeastern to the northwestern part of Chubu. The shape of the aseismic PHS slab inferred from our tomographic study coincides with that estimated from the analysis of $S$ to $S p$ conversion by Yamaoka and Nishihara (1997).

At the depths of $80 \mathrm{~km}$ (Fig. 9) and $100 \mathrm{~km}$ (Fig. 10), $\mathrm{HV}$ anomalies indicating the PAC slab are clearly seen in 

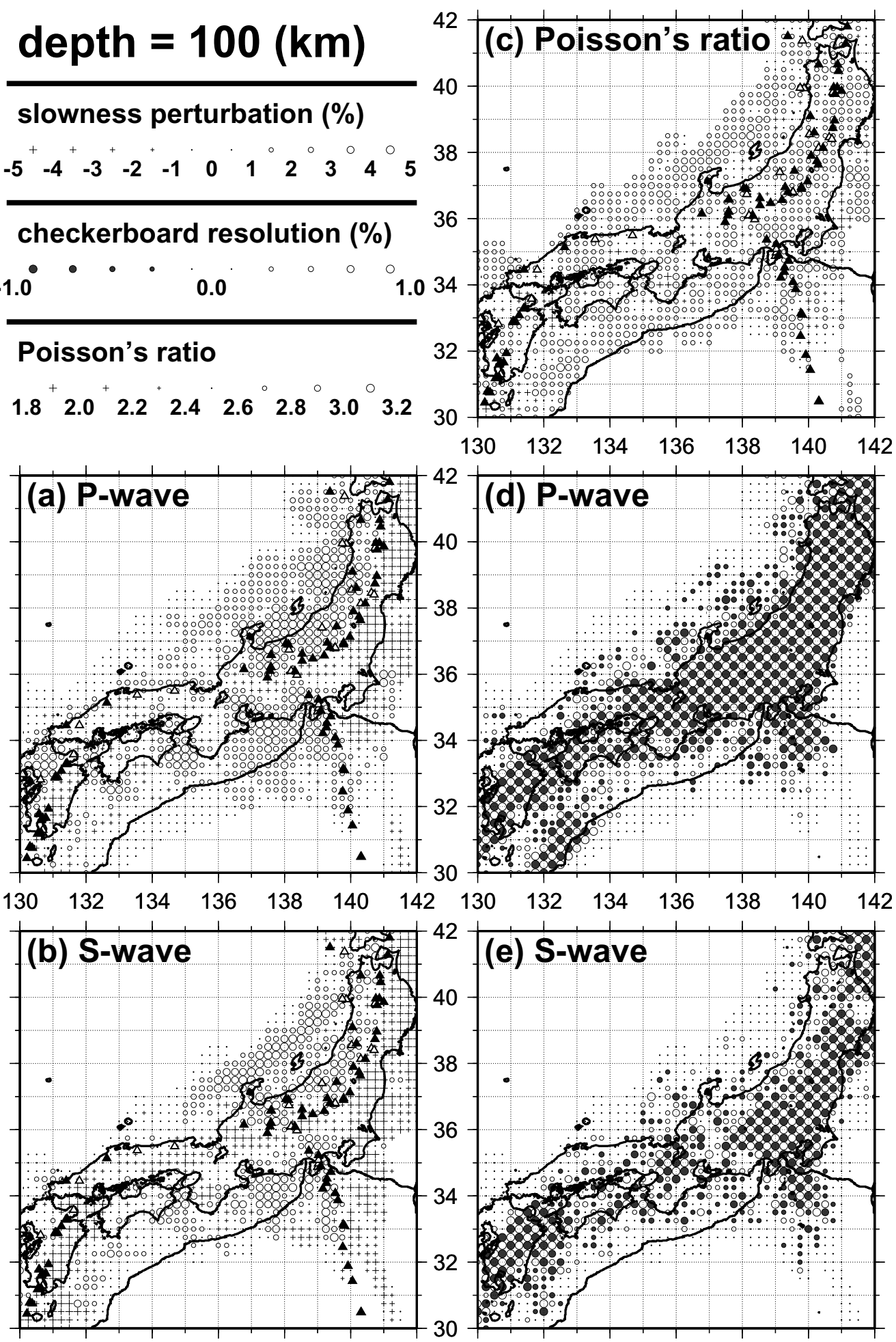

Fig. 10. Same as Fig. 8 except for the depth of $100 \mathrm{~km}$.

Tohoku, to the eastern rim at the depth of $80 \mathrm{~km}$ and to the volcanic front at the depth of $100 \mathrm{~km}$. In the mantle wedge, LV anomalies are remarkable. Similar features of the velocity anomalies are seen in Kyushu: The HV anomalies indicating the PHS slab reach volcanic front at the depth of $100 \mathrm{~km}$. In the middle part of Chubu and Kanto, the $\mathrm{HV}$ anomaly belt is running in the east-west direction at the depth of $100 \mathrm{~km}$ on the southern side of the active volcanoes including Hakusan Volcano, Ontake Volcano, and Asama
Volcano. This HV anomaly belt may indicate the aseismic PHS slab subducting at a high angle from the south.

\section{Subduction of PHS Slab -Vertical Cross Sections-}

We show the vertical cross sections of the slowness perturbations, checkerboard resolutions, and Poisson's ratios for the five profiles indicated in Fig. 12. The location and direction of these profiles are selected based on the hypocenter 


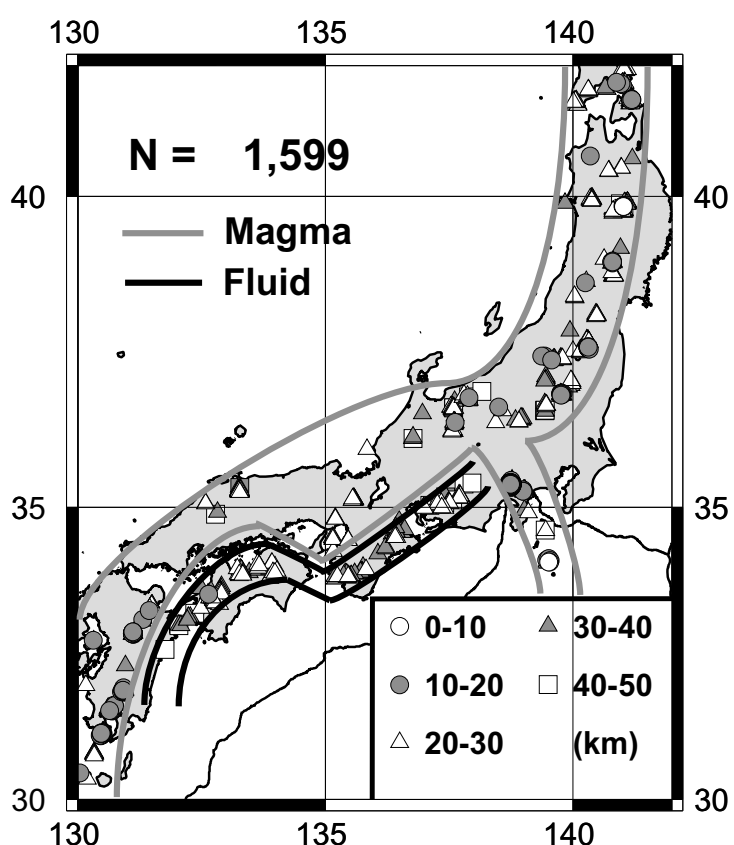

(a)

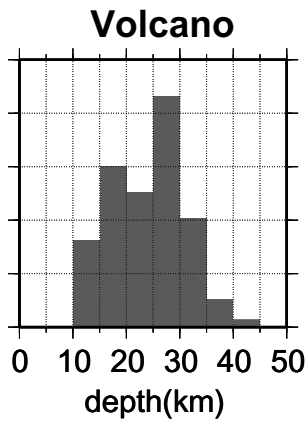

$\mathrm{Kii}$

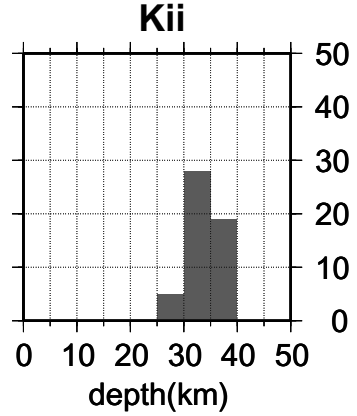

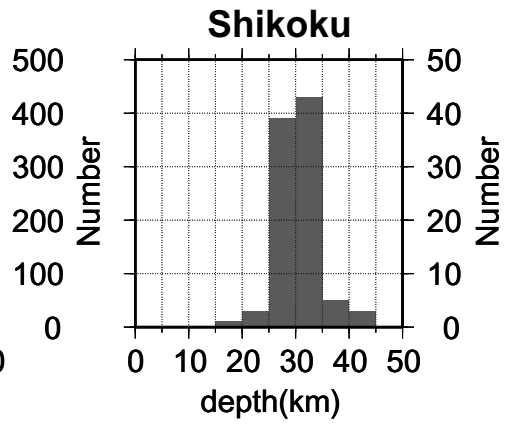

Tokai

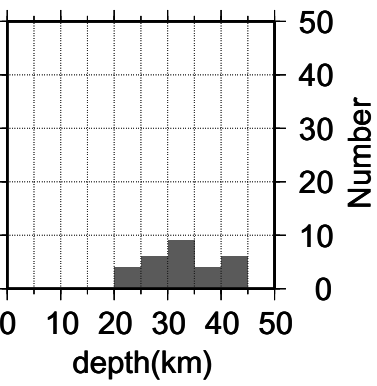

(b)

Fig. 11. (a) Epicentral distribution of 1,599 DLF earthquakes processed with close coordination of the Japan Meteorological Agency with the Ministry of Education, Culture, Sports, Science and Technology during the period from October 1997 to June 2002. (b) Depth distribution of the DLF earthquakes in volcanic regions and three nonvolcanic regions.

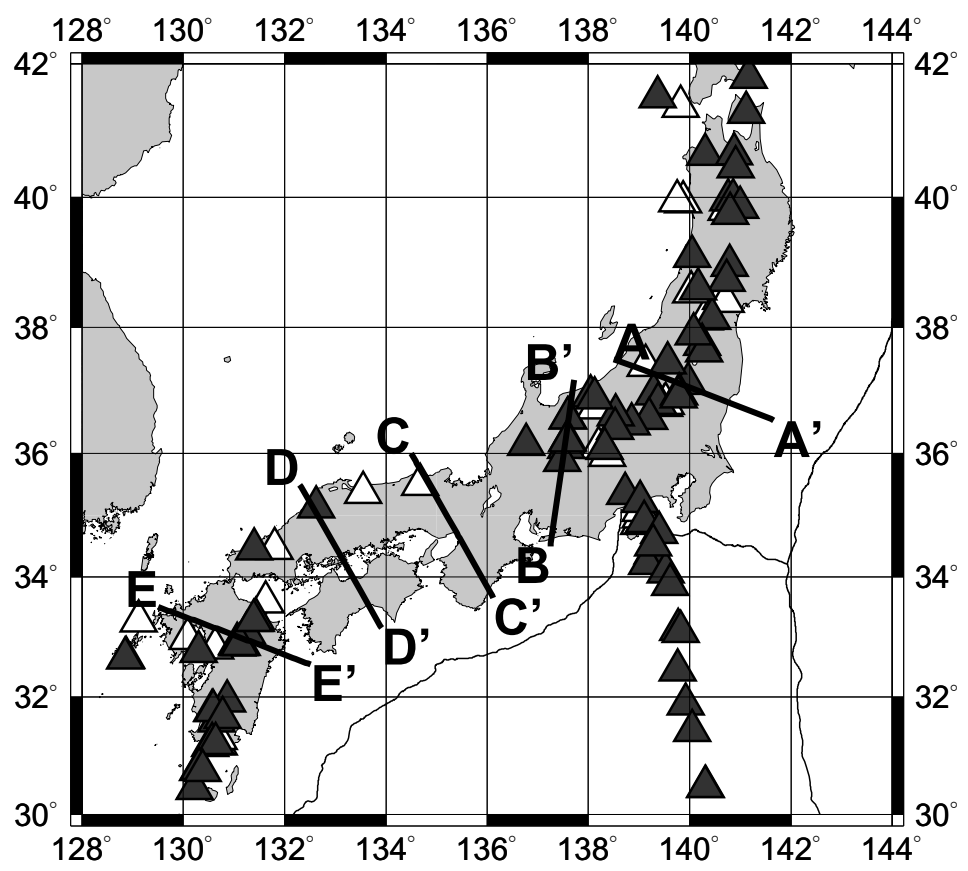

Fig. 12. Locations of the five vertical cross sections shown in Figs. 13-17. Solid and open triangles indicate presently active and inactive Quaternary volcanoes, respectively.

distribution of subcrustal earthquakes in order to delineate the shape of the PHS or PAC slab in each typical subduction region. In the vertical cross sections (Figs. 13 to 17), the presentation of the checkerboard resolution is different from conventional one adopted in the horizontal cross sections (Figs. 6 to 10). The ratio of the obtained slowness preturbation with respect to correct one is presented in precent. Positive and negative signs mean that the obtained slowness perturbations show the same and opposite signs to the correct one, respectively. Thus 100 percent with positive sign indicates complete resolution.

Figure 13 shows the vertical cross section A-A' in the southern part of Tohoku through Nasu Volcano. Along this profile, the DLF earthquakes are located beneath the volcanic front or its back arc region, and cluster nearly vertically. The vertical clustering of the DLF earthquakes is often observed 


\section{A - $\mathbf{A}^{\prime}$}

slowness perturbation (\%)

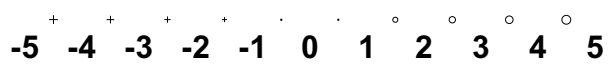
checkerboard resolution (\%)

$-15^{\bullet} 0^{\circ} 15^{\circ} 30 \quad 100$

\section{Poisson's ratio}

$\begin{array}{llllllll}1.8^{+} & 2.0^{+} & 2.2^{+} & 2.4 & 2.6^{\circ} & 2.8^{\circ} & 3.0^{\circ} & 3.2\end{array}$ (c) Poisson's ratio

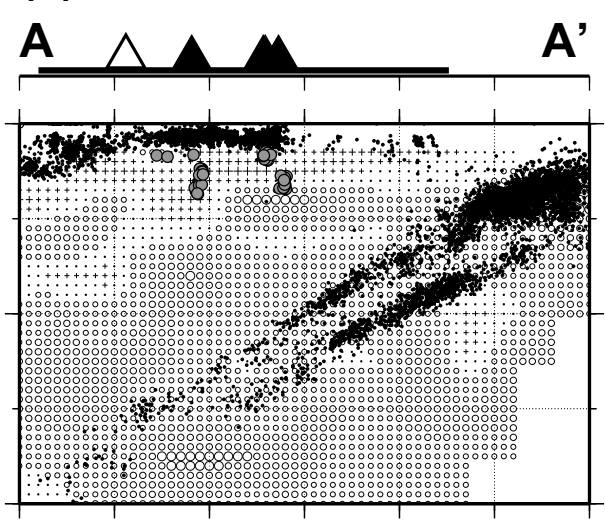

(d) P-wave
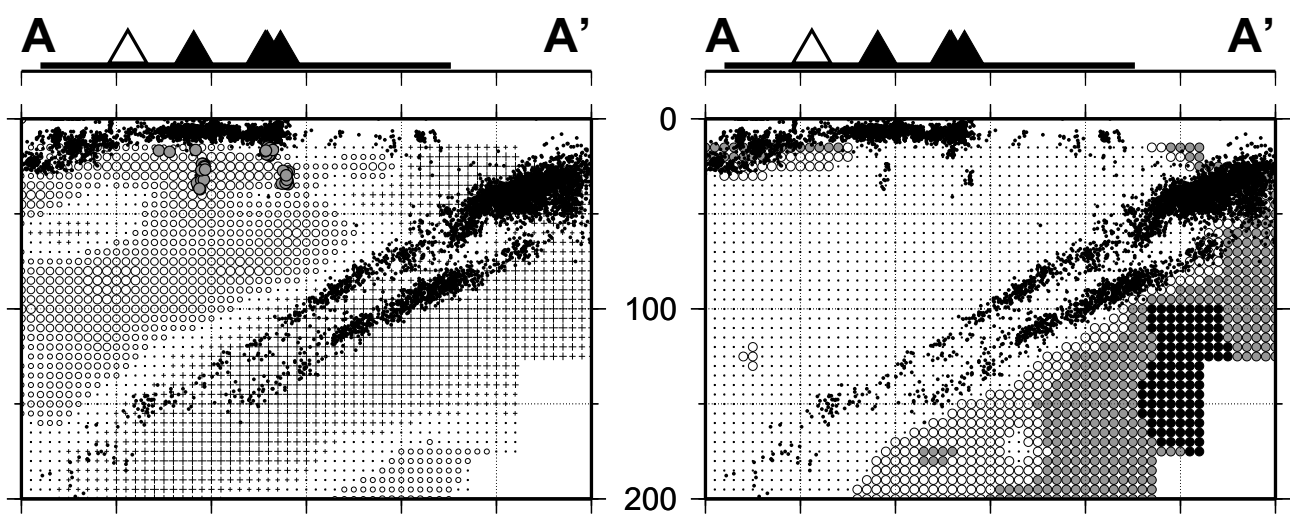

(e) S-wave

(b) S-wave

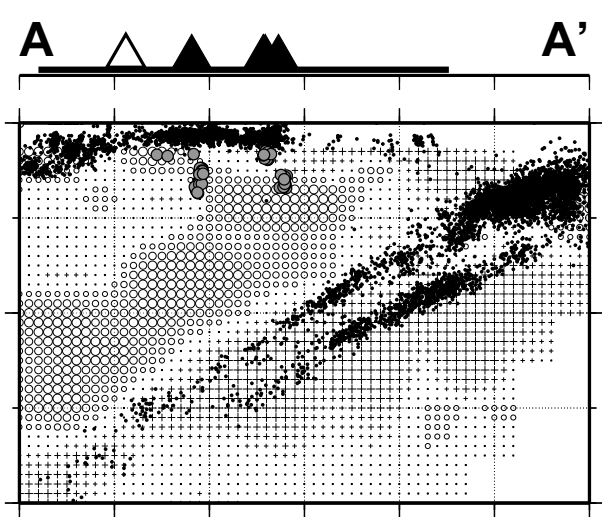

$A^{\prime}$

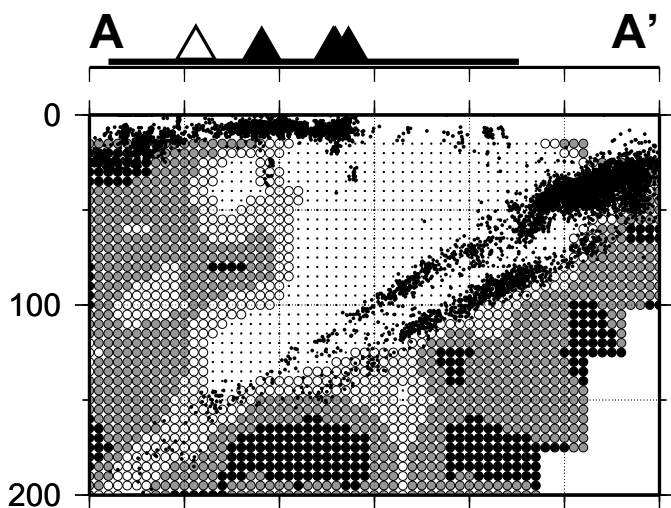

Fig. 13. Vertical cross sections of slowness perturbations ((a) $P$-wave and (b) $S$-wave), (c) Poisson's ratio, and checkerboard resolutions ((d) $P$-wave and (e) $S$-wave) obtained for the profile A-A' indicated in Fig. 12. In the figures of the slowness perturbations, crosses and circles denote high and low velocity anomalies compared to the reference velocity model, respectively. In the figure of the Poisson's ratio, crosses and circles denote low and high Poisson's ratio anomalies, respectively. In the figures of the checkerboard resolutions, the resolutions are good in the regions of small dots. Further information on the vertical plot of the checkerboard resolution is explained in text. Dots and grey circles indicate all earthquakes and the DLF earthquakes located along the profile within a width of $0.25^{\circ}$, processed with close coordination of the Japan Meteorological Agency with the Ministry of Education, Culture, Sports, Science and Technology, during the period from October 1997 to June 2002, respectively. The land area is shown at the top of each figure by thick line. Solid and open triangles indicate presently active and inactive Quaternary volcanoes, respectively.

in volcanic regions. It may be due to the ascent of melt or volatile materials. We find thick $\mathrm{HV}$ anomalies indicating the PAC slab and LV anomalies suggesting the ascent of hot mantle flow in the mantle wedge. This result is consisitent with recent tomographic studies on this region (Zhao et al., 1992; Nakajima et al., 2001).
Figure 14 shows the vertical cross section B-B' through the Norikura volcanic zone in Chubu (Fig. 12). Along the Norikura volcanic zone, high-K lavas are observed (e.g., Kaneko, 1995), which supports the idea that the volcanism on the back arc side of the northeastern Japan arc is caused by the PAC slab. However, considering the activity of the 


\section{B - B'}

slowness perturbation (\%)

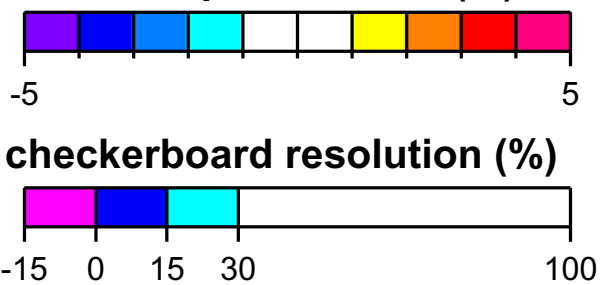

\section{Poisson's ratio}

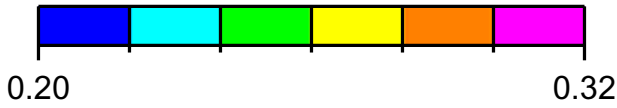

(a) P-wave

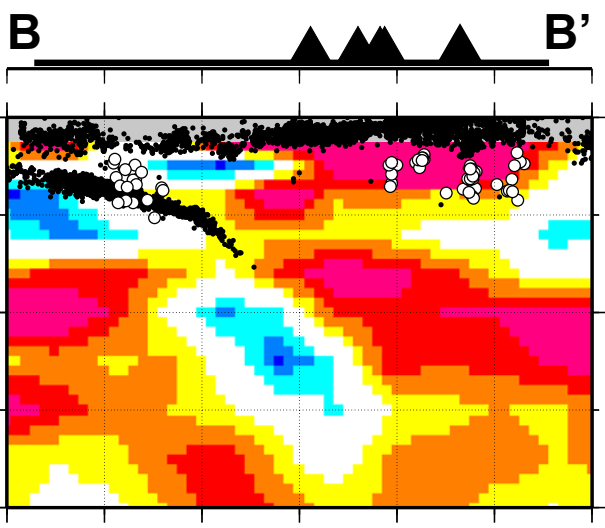

(b) S-wave

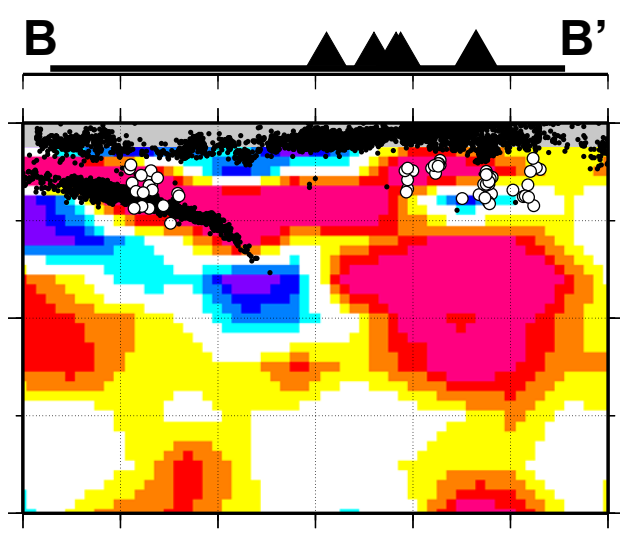

(c) Poisson's ratio

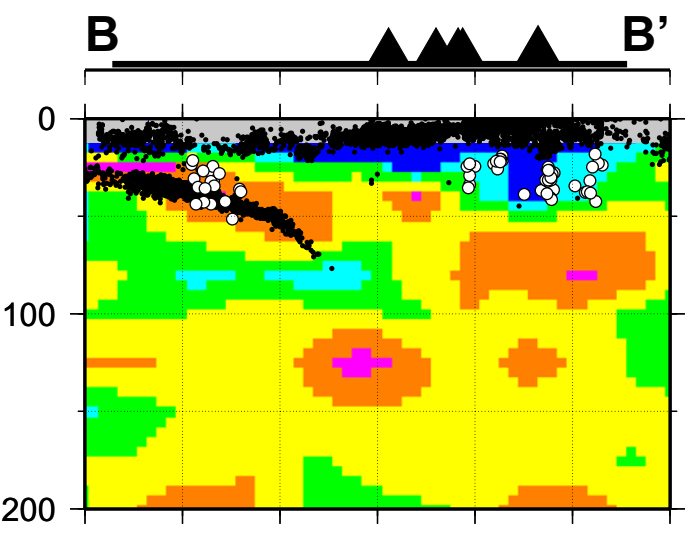

(d) P-wave

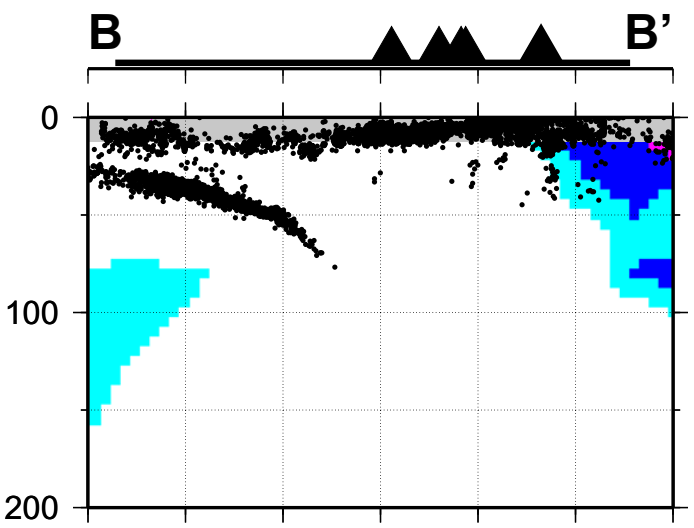

(e) S-wave

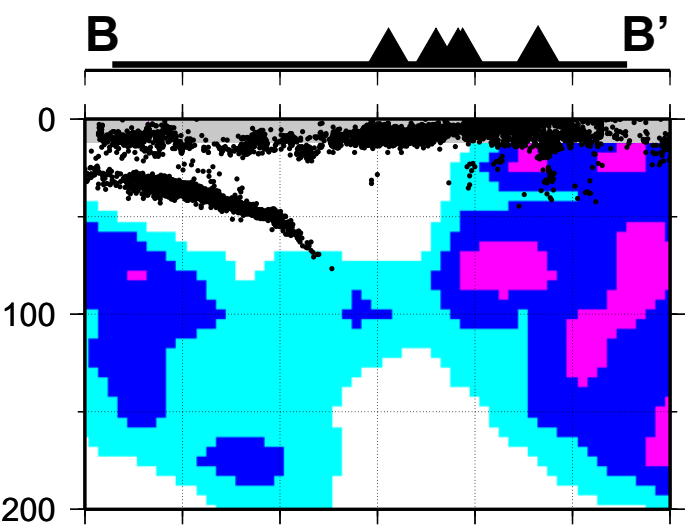

Fig. 14. Same as Fig. 13 except for the profile B-B' in Fig. 12 and symbol conventions. In the figures of the slowness perturbations, cold and hot colors denote high and low velocity anomalies, respectively. In the figure of the Poisson's ratio, cold and hot colors denote low and high Poisson's ratio anomalies, respectively. In the figures of the checkerboard resolutions, the resolutions are good in white regions. Dots and open circles indicate all earthquakes and the DLF earthquakes.

volcanoes and the chemical composition of the lavas, Kimura and Yoshida (1996) suggest that the Quaternary volcanism along the Norikura volcanic zone is generated by the PHS slab subducting from the south. We examine the possibility of the magma generation from the PHS slab in this region.

We can delineate the upper boundary of a seismic slab from hypocenter distribution of subcrustal earthquakes. The seismic PHS slab subducts at a low angle to a depth of about
$50 \mathrm{~km}$, and then bends downward and subducts at a high angle to a depth of about $70 \mathrm{~km}$ right before Ontake Volcano, the southern end of the Norikura volcanic zone. In the figure of the $P$-wave slowness perturbations (Fig. 14(a)), we find $\mathrm{HV}$ anomalies indicating the PHS slab right beneath the subcrustal earthquakes with a low dip angle, but no HV anomalies beneath the subcrustal earthquakes near downward bending. The clear HV anomalies continue from the seismic PHS 


\section{C - C'}

slowness perturbation (\%)

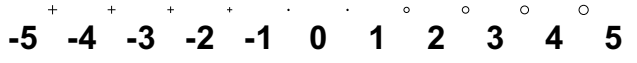
checkerboard resolution (\%)

$-15^{\bullet} \quad 0^{\circ} 15^{\circ} 30 \quad 100$

\section{Poisson's ratio}

$\begin{array}{lllllllll}1.8^{+} & 2.0 & 2.2 & 2.4 & 2.6 & 2.8^{\circ} & 3.0 & 3.2\end{array}$

(a) P-wave
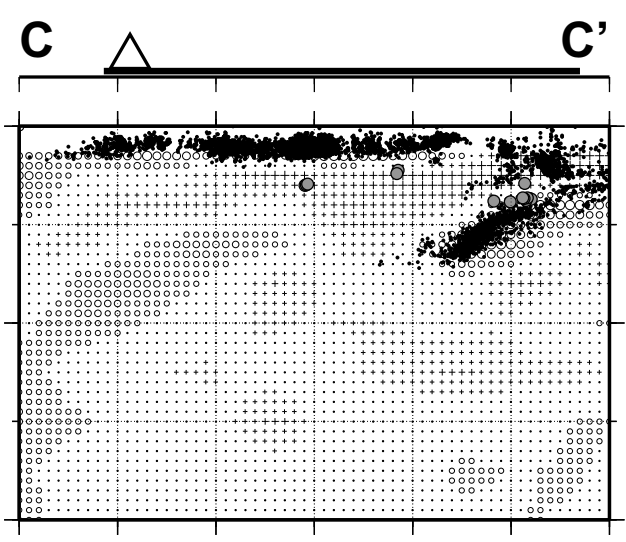

(b) S-wave

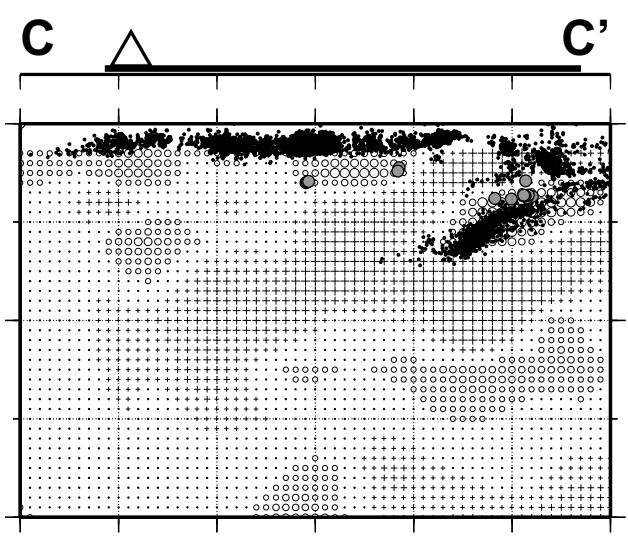

(c) Poisson's ratio

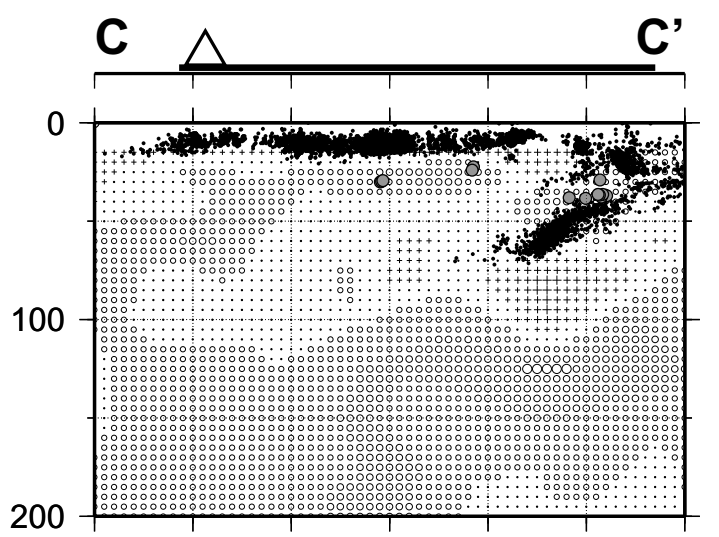

(d) P-wave

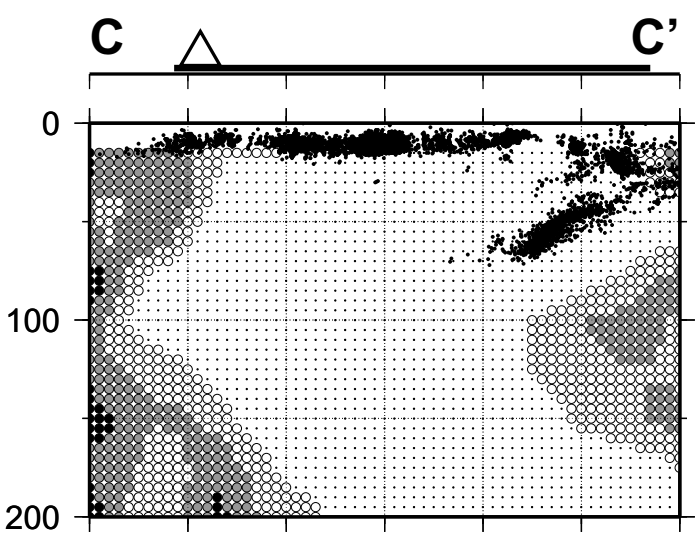

(e) S-wave

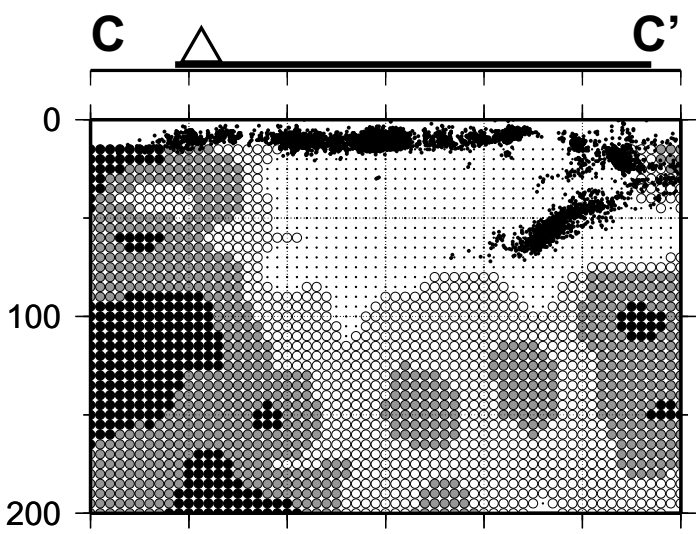

Fig. 15. Same as Fig. 13 except for the profile C-C' indicated in Fig. 12.

slab to a depth of about $150 \mathrm{~km}$ and may be considered as the aseismic continuation of the PHS slab. The aseismic PHS slab subducts at a high angle and reaches right beneath Ontake Volcano. The absence of the HV anomalies near downward bending and the high dip angle of the aseismic part are also seen in the result of Nakamura et al. (2002). The PHS slab extends to the southern end of the Norikura volcanic zone, but does not underlie the whole volcanic zone. Thus the PHS slab does not seem to induce convective circulation in the mantle wedge beneath the Norikura volcanic zone. The LV anomalies beneath the volcanic zone, probably representing the high temperature condition of the upper mantle beneath Chubu, may be caused by the subduction of the PAC slab from the east, and influence the brittle-ductile transition of the PHS slab. The aseismic part of the PHS slab below $100 \mathrm{~km}$ (Fig. 14(a)) is characterized by HP anomaly (Fig. 14(c)).

The DLF earthquakes in nonvolcanic regions are located near the upper boundary of the PHS slab or in the mantle wedge, or near the Moho discontinuity, in the depth range 
of $30-50 \mathrm{~km}$ (Fig. 14). The vertical clustering of the DLF earthquakes is clearly seen in volcanic regions, but not in nonvolcanic regions (Fig. 14). In the figure of Poisson's ratio (Fig. 14(c)), we find the coincidence of the HP anomalies and the DLF earthquakes in nonvolcanic region, as already mentioned on the horizontal cross sections. The HP anomalies in this region may indicate the presence of fluid which generates the DLF earthquakes. However, the HP anomalies are seen all over the upper boundary of the PHS slab to a depth of about $60 \mathrm{~km}$, and it is unlikely that all the HP anomalies are caused by the separated fluid. Probably the HP anomalies in the south from the DLF earthquakes (Fig. 14(c)), shallower than the Moho discontinuity, represent hydrated basaltic or gabbroic oceanic crust overlying the PHS slab. Basalt and gabbro show high Poisson's ratios $(\sim 0.29)$ at 1 GPa (Christensen, 1996). The thickness of the oceanic crust is $5-10 \mathrm{~km}$ (Takahashi, 2000), but the grid interval in the vertical direction at this depth is $15 \mathrm{~km}$, therefore we must have obtained a little blurred image of the oceanic crust. We suggest that the fluid released from the subducting oceanic crust generates the DLF earthquakes.

We can interpret the HP anomalies in the north from the DLF earthquakes (Fig. 14(c)) in the following two ways. First, the hydrated oceanic crust mentioned above may subduct to deeper region. Hori et al. (1985) show that basaltic oceanic crust subducts with the PHS slab down to at least the depth of $50-60 \mathrm{~km}$ beneath Chubu and the Kii peninsula from the analysis of $P$ and $S$ later phases. This depth approximately coincides with the edge of the HP anomalies. Second, hydrous minerals, such as serpentine and chlorite may be formed at the base of the overlying mantle wedge by the fluid released from the oceanic crust, and be brought down to deeper region with the subduction of the PHS slab (e.g., Iwamori, 1998). Kamiya and Kobayashi (2000) interpret HP anomalies in the depth range of 20-45 $\mathrm{km}$ near the upper boundary of the PHS slab beneath Kanto as serpentinized peridotite. However, the value of Poisson's ratio obtained in our study is not so high as that of serpentine from laboratory measurements $(\sim 0.35)$ (Christensen, 1996). This discrepancy might be due to the localization of serpentine or the adoption of the threshold value $( \pm 10 \%)$ of the slowness perturbations in our study. Serpentine is stable up to about $2 \mathrm{GPa}$, an equivalent depth of which is about 60 $\mathrm{km}$ under normal temperature conditions (Uto and Tatsumi, 1996), and this depth also coincides with the edge of the HP anomalies.

We cannot conclude which is the main cause of the HP anomalies near the upper boundary of the PHS slab only from our tomographic study because of the limit of resolution. However, both of the two interpretations indicate the presence of hydrous minerals which transport $\mathrm{H}_{2} \mathrm{O}$ to deeper region. The HP anomalies extend to the region where the PHS slab bends downward right before Ontake Volcano, and disappear after that. $\mathrm{H}_{2} \mathrm{O}$ may be transported down to this area with the subduction of the PHS slab. The downward bending of the PHS slab appears also in Kyushu, and may exhibit a certain boundary of physical properties of the PHS slab, which will be discussed later on. The HP anomalies disappear before the Norikura volcanic zone, accordingly a certain mechanism of the northward long-distance migration of fluid from the edge of the HP anomalies is required if the fluid is supplied to the mantle wedge beneath the Norikura volcanic zone.

Figure 15 shows the vertical cross section C-C' in Kinki including the Kii peninsula (Fig. 12). There is no indication of Quaternary volcanism in the Kii peninsula. The seismic PHS slab subducts to a depth of about $70 \mathrm{~km}$ at a higher angle than that in Chubu (Fig. 14(a)). In the figures of both $P$ and $S$-wave slowness perturbations, subcrustal earthquakes are located in the LV anomalies beneath the Kii peninsula. This characteristic is seen also in the result of Seno et al. (2001). Prominent $P$-wave HV anomalies indicative of the PHS slab are not apparent in Fig. 15(a). The resolutions are good for the region (Fig. 15(d)), thus these images are reliable. Probably these features are caused by the concentration of fluid: in this region, the young PHS slab subducts at a high angle, and the dehydration of oceanic crust occurs in a narrow zone. A large amount of fluid in a narrow zone has influence on the results of tomography. Seno et al. (2001) suggest the serpentine dehydration as the origin for the low velocity anomaly beneath the Kii peninsula. Wakita et al. (1987) observe anomalously high ${ }^{3} \mathrm{He} /{ }^{4} \mathrm{He}$ ratios from the natural gases in nonvolcanic Kinki, and suggest the presence of shallow magmatism. Probably a large volume of fluid of deep origin mentioned above contributes to the high emanation of ${ }^{3} \mathrm{He}$. HP anomalies are located with the DLF earthquakes at a depth of about $25 \mathrm{~km}$ beneath the middle part of Kinki, and they might indicate the sources of the high $-{ }^{3} \mathrm{He}$ gases.

Figure 16 shows the vertical cross section D-D' in Chugoku and Shikoku through Sambe Volcano (Fig. 12). Quaternary volcanoes are distributed in a line in the northern part of Chugoku. Hypocenter distribution of subcrustal earthquakes suggests that the seismic PHS slab subducts nearly horizontally to the southern part of Chugoku to a depth of about $50 \mathrm{~km}$. The HV anomalies of $P$ - and $S$ wave indicating the seismic PHS slab are located beneath the southern part of Chugoku. In the figure of the $P$-wave slowness perturbations (Fig. 16(a)), we find the aseismic PHS slab subducting to the northern area at a higher angle than the seismic one, to a depth of about $60 \mathrm{~km}$. Similar shape of the PHS slab is obtained by Shiomi (2002), Shiomi et al. (2002), and Yamauchi et al. (2003) from receiver function analyses. However, the resolutions are not good for the mantle beneath Sambe Volcano in the northern part of Chugoku (Figs. 16(d) and (e)), where the aseismic continuation of the PHS slab has been suggested (Nakanishi, 1980; Nakanishi et al., 1981).

Thin HP anomalies and $S$-wave LV anomalies spread right above the upper boundary of the PHS slab as seen in Chubu, and may indicate the presence of hydrous materials such as basaltic or gabbroic oceanic crust and serpentinized peridotite as mentioned above. Ohkura (2000) analyzes $P$ and $S$ later phases and suggests the presence of oceanic crust and the absence of mantle wedge beneath the central and the southern part of Shikoku. Therefore the HP anomalies and $S$-wave LV anomalies in this region may indicate the oceanic crust of the PHS slab. The occurrence of the DLF earthquakes in the northern part of Shikoku may be related to the presence of narrow mantle wedge above the slab. 


\section{D - D'}
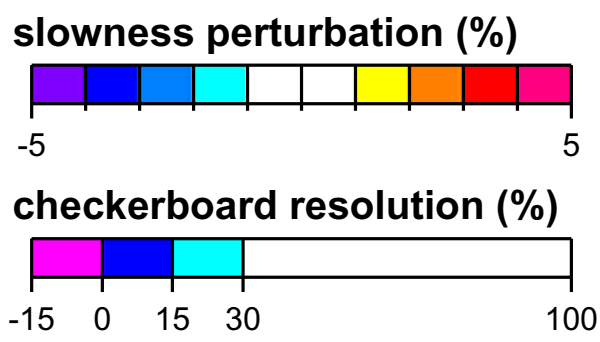

\section{Poisson's ratio}

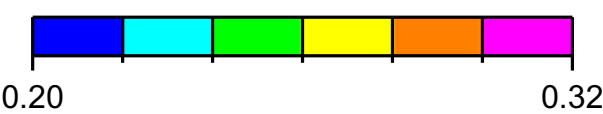

(a) P-wave
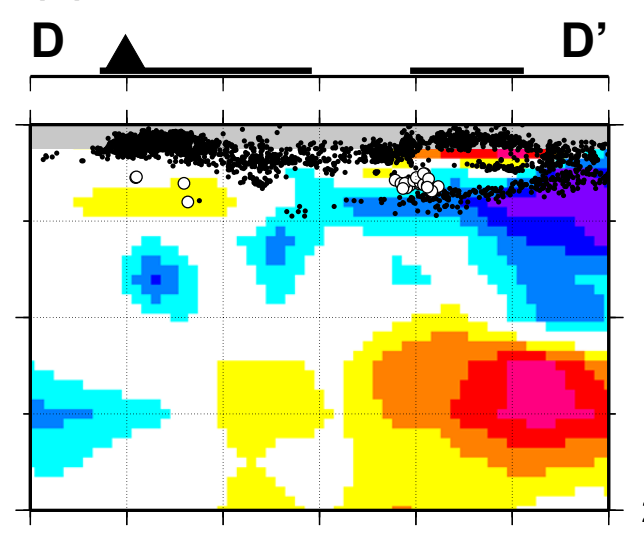

(b) S-wave

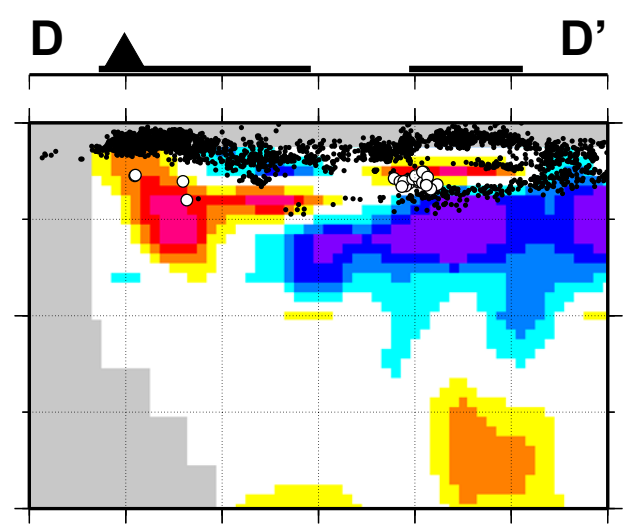

200

(c) Poisson's ratio

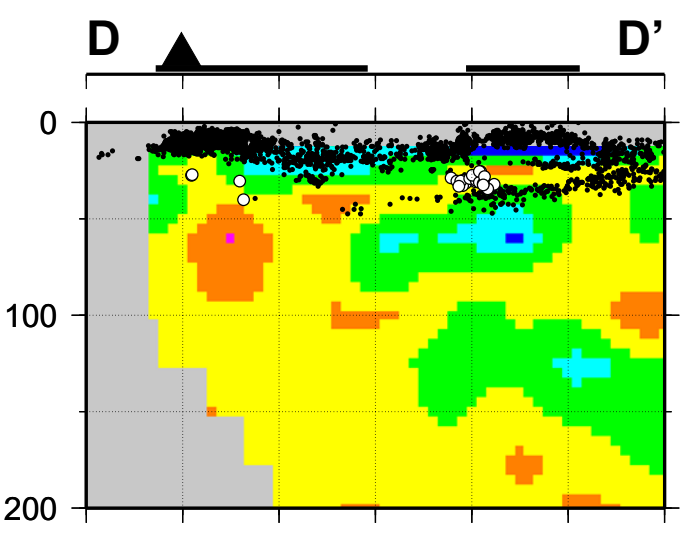

(d) P-wave

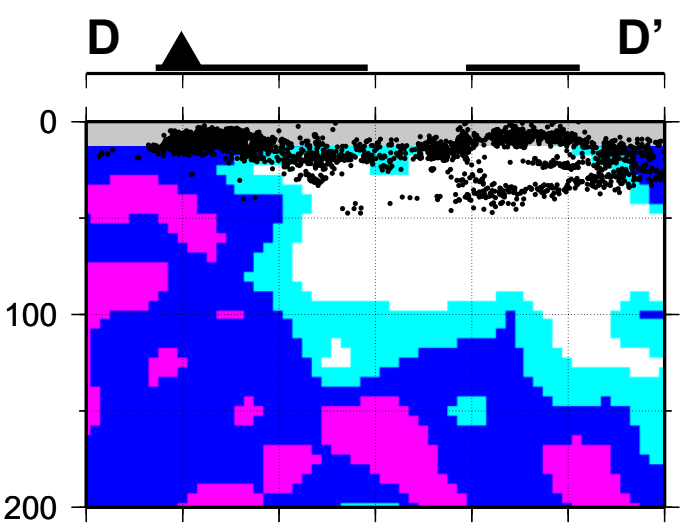

(e) S-wave

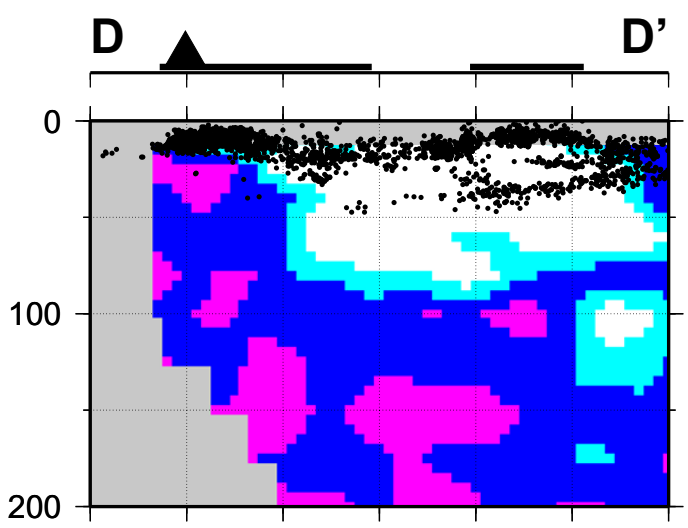

Fig. 16. Same as Fig. 14 except for the profile D-D' indicated in Fig. 12.

Some studies argued that the volcanism in Chugoku had been caused by the upwelling of mantle materials associated with the opening of the Sea of Japan, from analyses of eruption volume, chemical composition, and K-Ar dating of rocks (e.g., Iwamori, 1989; Uto, 1995): they suggested a possibility that the magmatism had not been caused by the subduction of the PHS slab.

The limited resolution for the velocity structure of the northern part of Chugoku prevents us from reaching rigid answers to the important questions whether the subduction of the PHS slab caused the volcanism in the northern part of Chugoku, whether the aseismic PHS slab reached the mantle beneath Quaternary volcanoes and induced the effective mantle wedge convection, and whether $\mathrm{H}_{2} \mathrm{O}$ was transported there with the subduction of the PHS slab.

However, we can deny a shallow subduction of the aseismic PHS slab beneath Quaternary volcanoes in northern Chugoku. In the central Andes, volcanoes exist in the area where slab subducts at a moderate angle, but no volcano in the area where slab subducts nearly horizontally. Con- 


\section{$E$ - E'}
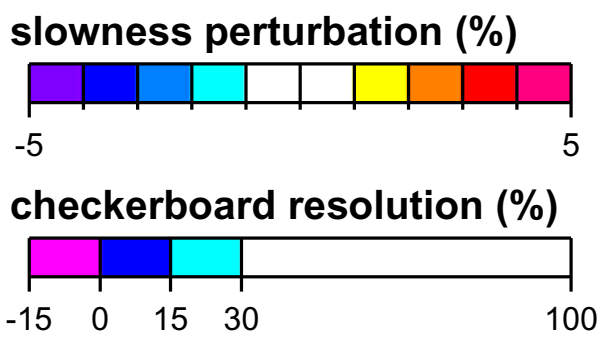

\section{Poisson's ratio}

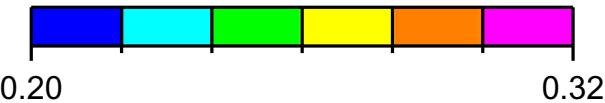

(a) P-wave
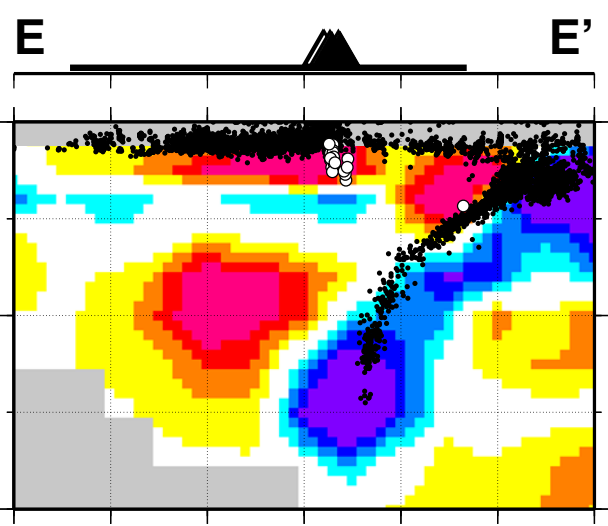

200

\section{(c) Poisson's ratio}

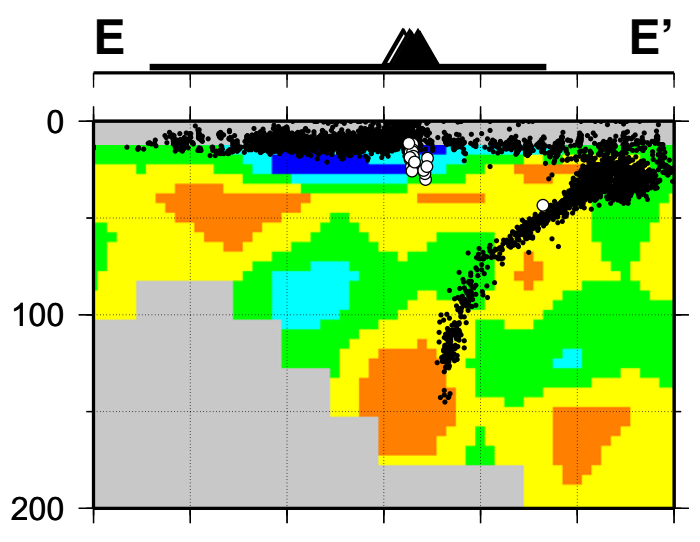

(d) P-wave

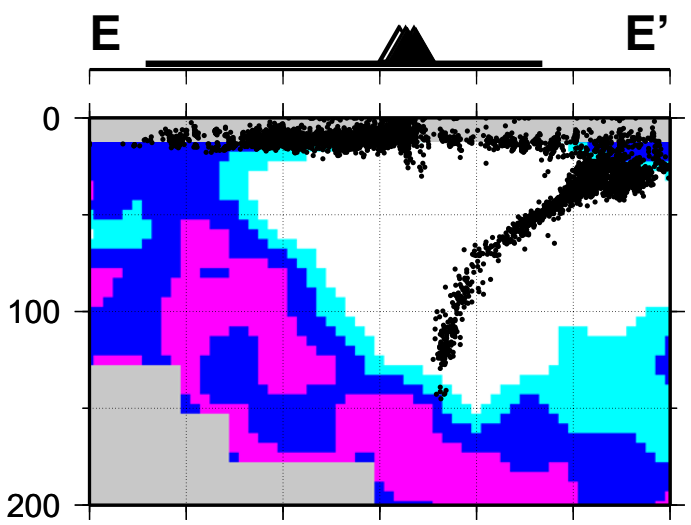

(e) S-wave

(b) S-wave

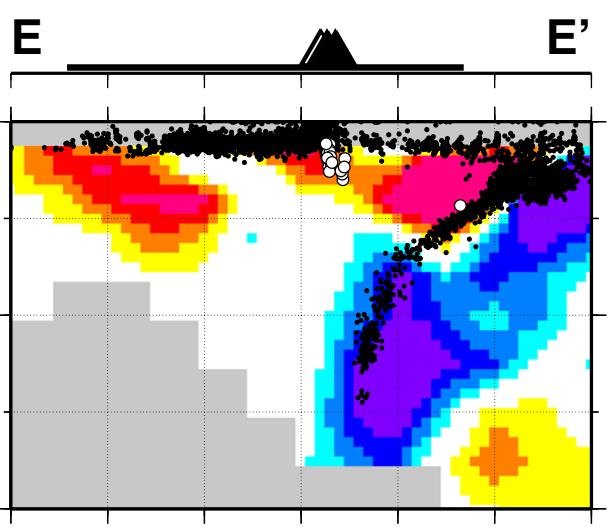

E'

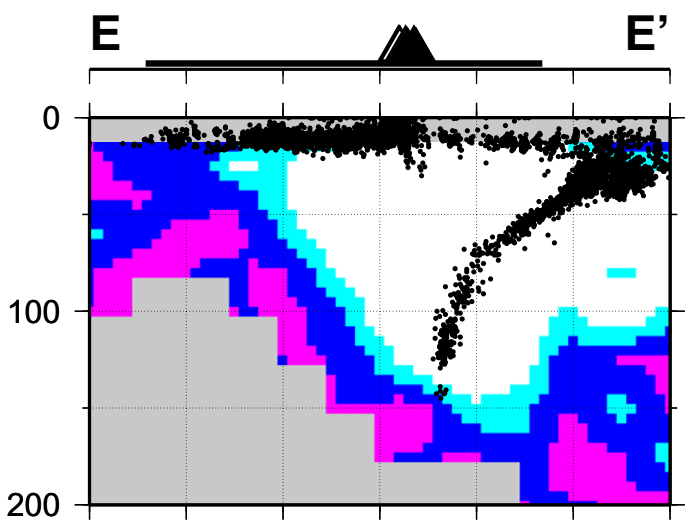

Fig. 17. Same as Fig. 14 except for the profile E-E' indicated in Fig. 12.

sidering this fact, Isacks and Barazangi (1977) pointed out the importance of ascending high temperature flow from deeper mantle caused by the induced convection, in subduction magmatism. If aseismic PHS slab with a low dip angle had existed in the northern part of Chugoku, volcanism would not have occurred there; the PHS slab would not have induced effective mantle wedge convection, and would have interrupted possible upwelling of mantle materials. Therefore the aseismic PHS slab may subduct at a high angle in the northern part of Chugoku if the subduction of the PHS slab is a cause for the volcanism. Tomographic studies using teleseismic events will provide us with important information for the volcanism in this region (e.g., Ochi et al., 2001), because the arrival time data from teleseismic events improve the resolution of the upper mantle beneath the Japan Sea side of the Chugoku region.

Figure 17 shows the vertical cross section E-E' in the northern part of Kyushu through Aso and Kuju Volcanoes. Clear volcanic front is formed by active volcanoes in this region, which is very different from the other regions in 
southwestern Japan. The seismic PHS slab subducts at a high angle to a depth of about $70 \mathrm{~km}$, and then bends downward and subducts nearly vertically to a depth of about $150 \mathrm{~km}$. We find the HV anomalies indicating the PHS slab down to a depth of about $150 \mathrm{~km}$, but the resolutions are poor at depths greater than $150 \mathrm{~km}$. In the results of both $P$ - and $S$-wave slowness perturbations (Figs. 17(a) and (b)), remarkable LV anomalies are seen on the forearc side of the mantle wedge right above the PHS slab, indicating the presence of aqueous fluid or melt. These LV anomalies extend to near the Moho discontinuity beneath active volcanoes. The LV anomalies imaged in the present study are shallower and closer to the Nankai trough than those obtained by Zhao et al. (2000b). The concentration of dehydration reactions occurs due to the high dip angle of the PHS slab, and weakens the HV anomalies indicating the underlying PHS slab in the depth range of 50-70 km. The LV anomalies in the forearc mantle wedge disappear near the region where the PHS slab bends downward, the same as in Chubu, therefore the supply of fluid to the mantle wedge does not occur at depths greater than about $70 \mathrm{~km}$.

In the figure of the $P$-wave slowness perturbations (Fig. 17(a)), we find notable LV anomalies on the backarc side of the mantle wedge in the depth range of 70-140 km. No apparent LV anomalies of $S$-wave are seen there, therefore the LV anomalies of $P$-wave do not show the presence of fluid or melt, but show high temperature condition of the mantle wedge. The effective mantle wedge convection due to the deep subduction of the PHS slab causes the ascent of hot mantle materials from deeper region. The volcanism in Kyushu has the advantages of the fluid concentration and the effective mantle wedge convection, compared to the volcanism in the other regions of southwestern Japan, therefore the volcanism in Kyushu is active.

\section{Seismological Constraints on Magmatism in Southwestern Japan}

Our study of travel time tomography has shown the following characteristics of the uppermost mantle structure, including the PHS slab, beneath southwestern Japan.

In some nonvolcanic regions, remarkable HP anomalies are found in the depth range of 25-40 km near the upper boundary of the PHS slab or the Moho discontinuity, and coincide with the hypocenter distribution of the DLF earthquakes, suggesting the presence of fluid released from the underlying PHS slab. The HV anomalies indicating the PHS slab are imaged along the hypocenter distribution of subcrustal earthquakes, and the dip angle and the leading edge differ from region to region. The HP anomalies (and the LV anomalies of $S$-wave) are located not only in the region where the DLF earthquakes occur, but also all over the upper boundary of the PHS slab or the overlying mantle wedge down to a depth of about $60 \mathrm{~km}$, which may suggest the presence of separated fluid or hydrous minerals. Especially in the regions where the PHS slab subducts at a low angle, such as Shikoku and the southern part of Chubu, the HP anomalies indicative of hydrous minerals are observed as a thin layer right above the PHS slab, which indicates the northward transportation of $\mathrm{H}_{2} \mathrm{O}$ with the subduction of the slab. In the regions where the PHS slab subducts to deeper area, such as Chubu and Kyushu, its downward bending occurs in the depth range of 50-70 km. The HP anomalies near the upper boundary of the PHS slab disappear near the downward bending.

Basalt and gabbro which are the main components of the oceanic crust are transformed into eclogite under high pressure conditions, accompanied with the increase in density and the dehydration. Hori et al. (1985) point out that the PHS slab with the basaltic oceanic crust has positive buoyancy and that with eclogitic oceanic crust has negative buoyancy. The downward bending of the PHS slab in the depth range of 50-70 km shows a certain boundary of physical properties of the slab, therefore it is conceivable that this downward bending is caused by the increase in density of the oceanic crust due to the basalt-eclogite transition with the subduction of the PHS slab.

Hurukawa and Imoto (1993) find a non double-couple earthquake, which is considered to be due to the sudden volume contraction, at a depth of about $60 \mathrm{~km}$ in the oceanic crust of the PHS slab in Kanto, and conclude that gabbroor basalt-eclogite transition in the oceanic crust caused this earthquake. The depth of the downward bending of the PHS slab estimated in our study is consistent with the depth of the non double-couple earthquake.

In contrast, we find no obvious downward bending of the PAC slab beneath Tohoku, where the PAC slab subducts with a constant dip angle. It may be due to the fact that the oceanic crust occupies a small volumetric proportion of the PAC slab. Most of the PAC slab consists of the mantle composition, thus the influence of basalt-eclogite transition in the oceanic crust upon the subduction geometry of the PAC slab is small. However, the subduction geometry of the PHS slab in southwestern Japan is greatly affected by the sudden density change of the oceanic crust which occupies a considerable volumetric proportion of the PHS slab. The driving mechanism of the PHS slab composed of the two parts of the oceanic crust with positive and negative buoyancy should be different from that of the PAC slab subducting at a constant dip angle. Therefore in case of the deep subduction of the PHS slab, a different pattern of convection flow might be induced in the mantle wedge beneath southwestern Japan.

The HP anomalies (and the LV anomalies of $S$-wave) are found near the upper boundary of the PHS slab or the mantle wedge down to a depth of about $60 \mathrm{~km}$, and may suggest the presence of hydrous minerals, such as serpentinized peridotite and basaltic oceanic crust which transport $\mathrm{H}_{2} \mathrm{O}$ northward with the subduction of the PHS slab, or separated fluid released from them. We have not found yet a rigid answer to the question how and where the fluid is supplied from the hydrous minerals to the mantle wedge, but the supply of the fluid appears to end near the downward bending of the PHS slab, in the forearc region.

Analyzing phase conversion of body waves, Matsuzawa et al. (1986) show the presence of a thin low velocity layer on the surface of the PAC slab in the depth range of 60$150 \mathrm{~km}$ beyond the volcanic front in northeastern Japan, and interpret it as gabbroic oceanic crust. Their result suggests that fluid can be supplied from the PAC slab in both forearc and backarc regions, or beneath volcanic front. However, this low velocity layer has not been detected in studies of 
travel time tomography for Tohoku, probably because of the limit of resolution (e.g., Zhao et al., 1992; Nakajima et al., 2001). Thus the question about how and where the fluid is supplied to the mantle wedge has not been answered in their studies either. On the other hand, the supply of the fluid from the PHS slab is limited to the mantle wedge in the forearc region in southwestern Japan. In the northern part of Kyushu, clear volcanic front is separated from the location of the fluid supply from the PHS slab, which suggests the lateral migration of the fluid and/or melt generated by the influence of the slab.

\section{Conclusions}

We summarize the remarkable characteristics of the PHS slab which are different from those of the PAC slab.

(1) The PHS slab bends downward in the depth range of $50-70 \mathrm{~km}$, probably due to the increase in density of the oceanic crust caused by the basalt-eclogite transition with its subduction. (2) The supply of the fluid from the hydrous minerals overlying the PHS slab is limited to the mantle wedge in the forearc region, before Quaternary volcanoes.

These features have great influence on the subduction magmatism. Large regional differences of the subduction magmatism may have occurred in southwestern Japan because of the immatureness of the PHS slab, therefore it is still difficult to model the magmatism. However, the above two characteristics may be useful as the constraints on the modelling of the subduction and magmatism for southwestern Japan.

Acknowledgments. We are grateful to T. Yamane and S. Kamiya for allowing us to use their tomography codes and for their helpful advices for using the codes. We are also grateful to $\mathrm{Y}$. Furukawa for useful discussions about the interpretation of the results of tomography. We would like to thank D. Zhao, T. Seno, and E. Fukuyama for helpful comments on this paper. We used hypocenter and arrival time data processed with close coordination of the Japan Meteorological Agency with the Ministry of Education, Culture, Sports, Science and Technology. These data have been provided by the National Research Institute for Earth Science and Disaster Prevention, Hokkaido University, Hirosaki University, Tohoku University, the University of Tokyo, Nagoya University, Kyoto University, Kochi University, Kyushu University, Kagoshima University, National Institute of Advanced Industrial Science and Technology, and the Tokyo Metropolitan Government. We also used hypocenter and arrival time data collected from the Japan University Network Earthquake Catalog published by the Earthquake Research Institute, the University of Tokyo. This study was supported by Kurata Memorial Hitachi Science and Technology Foundation.

\section{References}

Aramaki, S. and T. Ui, Major element frequency distribution of the Japanese Quaternary volcanic rocks, Bull. Volcanol., 41, 390-407, 1978.

Christensen, N. I., Poisson's ratio and crustal seismology, J. Geophys. Res., 101, 3139-3156, 1996.

Hamada, N., Re-examination of travel time tables for local earthquakes, Pap. Meteorol. Geophys., 35, 109-167, 1984 (in Japanese with English abstract).

Hirahara, K., Three-dimensional seismic structure beneath southwest Japan: the subducting Philippine Sea plate, Tectonophysics, 79, 1-44, 1981.

Hirahara, K., Detection of three-dimensional velocity anisotropy, Phys. Earth Planet. Inter, 51, 71-85, 1988.

Honda, S. and I. Nakanishi, Shape of the Philippine Sea slab in the mantle and volcanism in the Chubu region, Central Japan, Geophys. Bull. Hokkaido Univ., 65, 167-177, 2002 (in Japanese with English abstract).

Hori, S., H. Inoue, Y. Fukao, and M. Ukawa, Seismic detection of the un- transformed 'basaltic' oceanic crust subducting into the mantle, Geophys J. R. Astr. Soc., 83, 169-197, 1985.

Hurukawa, N. and M. Imoto, A non double-couple earthquake in a subducting oceanic crust of the Philippine Sea Plate, J. Phys. Earth, 41, 257-269, 1993.

Inoue, H., Y. Fukao, K. Tanabe, and Y. Ogata, Whole mantle P-wave travel time tomography, Phys. Earth Planet. Inter., 59, 294-328, 1990.

Isacks, B. L. and M. Barazangi, Geometry of Benioff zones: lateral segmentation and downward bending of the subducted lithosphere, in Island Arcs, Deep Sea Trenches and Back-Arc Basins, edited by Talwani, M. and W. C. Pitman III, 470 pp, Amer. Geophys. Union, Washington, D. C., 1977.

Iwamori, H., Compositional zonation of Cenozoic basalts in the central Chugoku district, southwestern Japan: Evidence for mantle upwelling, Bull. Volcanol. Soc. Jpn., Ser. 2, 34, 105-123, 1989.

Iwamori, H., Transportation of $\mathrm{H}_{2} \mathrm{O}$ and melting in subduction zones, Earth Planet. Sci. Lett., 160, 65-80, 1998.

Japan Meteorological Agency, The Seismological and Volcanological Bulletin of Japan for January 2002, Japan Meteorological Agency, Tokyo, 2002.

Japan Meteorological Agency, http://www.jma.go.jp/JMA HP/jma/press/0301/21a/yochiren.pdf, 2003.

Kamiya, S. and Y. Kobayashi, Seismological evidence for the existence of serpentinized wedge mantle, Geophys. Res. Lett., 27, 819-822, 2000.

Kaneko, T., A kinematic subduction model for the genesis of back-arc low$\mathrm{K}$ volcanoes at a two-overlapping subduction zone, central Japan: another volcanic front originated from the Philippine Sea plate subduction, $J$. Volcanol. Geotherm. Res., 66, 9-26, 1995.

Kimura, J. and T. Yoshida, Magma supply system beneath the Norikura volcanic belt, Earth Monthly, 18, 97-103, 1996 (in Japanese).

Kincaid, C. and I. S. Sacks, Thermal and dynamical evolution of the upper mantle in subduction zones, J. Geophys. Res., 102, 12295-12315, 1997.

Kinoshita, Y. and I. Nakanishi, Subcrustal seismicity beneath the southern part of the Chugoku region, Japan, J. Phys. Earth, 45, 307-312, 1997.

Matsuzawa, T., N. Umino, A. Hasegawa, and A. Takagi, Upper mantle velocity structure estimated from PS-converted wave beneath the northeastern Japan Arc, Geophys. J. R. Astr. Soc., 86, 767-787, 1986.

Mibe, K., T. Fujii, and A. Yasuda, Control of the location of the volcanic front in island arcs by aqueous fluid connectivity in the mantle wedge, Nature, 401, 259-262, 1999.

Miyoshi, T. and K. Ishibashi, Geometry of the upper surface of the Philippine Sea slab (Preliminaries), Proc. Meet., DPRI, Kyoto Univ., 13K-7, 127-137, 2002 (in Japanese with English abstract).

Nakajima, J., T. Matsuzawa, A. Hasegawa, and D. Zhao, Three-dimensional structure of $\mathrm{V}_{p}, \mathrm{~V}_{s}$, and $\mathrm{V}_{p} / \mathrm{V}_{s}$ beneath northeastern Japan: Implications for arc magmatism and fluids, J. Geophys. Res., 106, 21843-21857, 2001.

Nakamura, M., H. Watanabe, T. Konomi, S. Kimura, and K. Miura, Characteristic activities of subcrustal earthquakes along the outer zone of southwestern Japan, Ann. Disas. Prev. Res. Inst. Kyoto Univ., 40, 1-20, 1997 (in Japanese with English abstract).

Nakamura, M., Y. Yoshida, D. Zhao, K. Yoshikawa, H. Takayama, G. Aoki, H. Kuroki, T. Yamazaki, J. Kasahara, T. Kanazawa, T. Sato, H. Shiobara H. Shimamura, and A. Nakanishi, Three-dimensional $\mathrm{P}$ and $\mathrm{S}$ wave velocity structure beneath central Japan, Pap. Meteorol. Geophys., 53, 1-28, 2002 (in Japanese with English abstract).

Nakanishi, I., Precursors to ScS phases and dipping interface in the upper mantle beneath southwestern Japan, Tectonophysics, 69, 1-35, 1980.

Nakanishi, I., K. Suyehiro, and T. Yokota, Regional variations of amplitudes of ScSp phases observed in the Japanese islands, Geophys. J. R. Astr. Soc., 67, 615-634, 1981.

Nakanishi, I., Y. Kinoshita, and K. Miura, Subduction of young plates: A case of the Philippine Sea plate beneath the Chugoku region, Japan, Earth Planets Space, 54, 3-8, 2002.

Obara, K., Nonvolcanic deep tremor associated with subduction in southwest Japan, Science, 296, 1679-1681, 2002.

Ochi, F., M. Nakamura, and D. Zhao, Deep structure of the subducting Philippine Sea slab under southwestern Japan, Earth Monthly, 23, 679684, 2001 (in Japanese).

Oda, H. and T. Douzen, New evidence for a low-velocity layer on the subducting Philippine Sea plate in southwest Japan, Tectonophysics, 332, 347-358, 2001.

Ohkura, T., Structure of the upper part of the Philippine Sea plate estimated by later phases of upper mantle earthquakes in and around Shikoku, Japan, Tectonophysics, 321, 17-36, 2000.

Seno, T., D. Zhao, Y. Kobayashi, and M. Nakamura, Dehydration of ser- 
pentinized slab mantle: Seismic evidence from southwest Japan, Earth Planets Space, 53, 861-871, 2001.

Shiomi, K., Heterogeneous structure of seismic velocity beneath the Chugoku and Shikoku regions based on receiver function analysis, $\mathrm{Ph} . \mathrm{D}$. Thesis, Tohoku Univ., 152 pp., 2002 (in Japanese).

Shiomi, K., K. Obara, and H. Sato, Location of subducting Philippine Sea Plate beneath Chugoku-Shikoku region revealed from receiver function analysis, Programme and Abstracts, Fall Meeting, Seismol. Soc. Jpn., A51, 2002 (in Japanese).

Takahashi, M., Island Arc, Magma and Tectonics, 322 pp, Univ. Tokyo Press, Tokyo, 2000 (in Japanese)

Tatsumi, Y., Migration of fluid phases and genesis of basalt magmas in subduction zones, J. Geophys. Res., 94, 4697-4707, 1989.

Ueno, H., S. Hatakeyama, T. Aketagawa, J. Funasaki, and N. Hamada, Improvement of hypocenter determination procedures in the Japan Meteorological Agency, Quarter. J. Seismol., 65, 123-134, 2002 (in Japanese with English abstract).

Um, J. and C. Thurber, A fast algorithm for two-point seismic ray tracing, Bull. Seismol. Soc. Am., 77, 972-986, 1987.

Uto, K., Volcanoes and age determination: Now and future of K-A and ${ }^{40} \mathrm{Ar} /{ }^{39} \mathrm{Ar}$ dating, Bull. Volcanol. Soc. Jpn., S40, 27-46, 1995 (in Japanese with English abstract).

Uto, K. and Y. Tatsumi, Quaternary volcanism of the Japanese Islands, Island Arc, 5, 250-261, 1996.

Wakita, H., Y. Sano, and M. Mizoue, High ${ }^{3} \mathrm{He}$ emanation and seismic swarms observed in a nonvolcanic, forearc region, J. Geophys. Res., 92 , 12539-12546, 1987.

Yamane, T., I. Nakanishi, and S. Kamiya, P-wave velocity structure of the
Philippine Sea plate subducting from the Nankai trough and its relation with seismicity and volcanism in Southwestern and Central Japan, Bull. Earthq. Res. Inst. Univ. Tokyo, 75, 335-374, 2000 (in Japanese with English abstract).

Yamaoka, K. and M. Nishihara, Geometry of subducting Philippine Sea plate and its relationship with the volcanism in Chubu district, Japan, Bull. Volcanol. Soc. Jpn., S42, 131-138, 1997 (in Japanese with English abstract).

Yamauchi, M., K. Hirahara, and T. Shibutani, High resolution receiver function imaging of the seismic velocity discontinuities in the crust and the uppermost mantle beneath southwest Japan, Earth Planets Space, 55, 5964, 2003.

Yamazaki, F. and T. Ooida, Configuration of subducted Philippine Sea plate beneath the Chubu district, central Japan, J. Seismol. Soc. Jpn., Ser. 2, 38, 193-201, 1985 (in Japanese with English abstract).

Zhao, D., A. Hasegawa, and S. Horiuchi, Tomographic imaging of $\mathrm{P}$ and $\mathrm{S}$ wave velocity structure beneath northeastern Japan, J. Geophys. Res., 97 , 19909-19928, 1992.

Zhao, D., F. Ochi, A. Hasegawa, and A. Yamamoto, Evidence for the location and cause of large crustal earthquakes in Japan, J. Geophys. Res., 105, 13579-13594, 2000a.

Zhao, D., K. Asamori, and H. Iwamori, Seismic structure and magmatism of the young Kyushu subduction zone, Geophys. Res. Lett., 27, 2057-2060, $2000 \mathrm{~b}$

I. Nakanishi (e-mail: ichiro@kugi.kyoto-u.ac.jp) 